\title{
The use of partial least squares path modeling in international marketing
}

DOI:

10.1108/S1474-7979(2009)0000020014

Link to publication record in Manchester Research Explorer

\section{Citation for published version (APA):}

Henseler, J., Ringle, C. M., \& Sinkovics, R. R. (2009). The use of partial least squares path modeling in international marketing. In Advances in International Marketing/Adv. Int. Mark. (Vol. 20, pp. 277-319). (Advances in International Marketing). Emerald Publishing Limited. https://doi.org/10.1108/S1474-7979(2009)0000020014

\section{Published in:}

Advances in International Marketing|Adv. Int. Mark.

\section{Citing this paper}

Please note that where the full-text provided on Manchester Research Explorer is the Author Accepted Manuscript or Proof version this may differ from the final Published version. If citing, it is advised that you check and use the publisher's definitive version.

\section{General rights}

Copyright and moral rights for the publications made accessible in the Research Explorer are retained by the authors and/or other copyright owners and it is a condition of accessing publications that users recognise and abide by the legal requirements associated with these rights.

\section{Takedown policy}

If you believe that this document breaches copyright please refer to the University of Manchester's Takedown Procedures [http://man.ac.uk/04Y6Bo] or contact uml.scholarlycommunications@manchester.ac.uk providing relevant details, so we can investigate your claim.

\section{OPEN ACCESS}




\title{
THE USE OF PARTIAL LEAST SQUARES PATH MODELING IN INTERNATIONAL MARKETING
}

\author{
Jörg Henseler, Christian M. Ringle and \\ Rudolf R. Sinkovics
}

The advent of structural equation modeling (SEM) with latent variables has changed the nature of research in international marketing and management. Researchers acknowledge the possibilities of distinguishing between measurement and structural models and explicitly taking measurement error into account. As Gefen, Straub, and Boudreau (2000, p. 6) point out, "SEM has become de rigueur in validating instruments and testing linkages between constructs." They furthermore distinguish between two families of SEM techniques: covariance-based techniques, as represented by LISREL, and variance-based techniques, of which partial least squares (PLS) path modeling is the most prominent representative.

PLS has been used by a growing number of researchers from various disciplines such as strategic management (e.g., Hulland, 1999), management information systems (e.g., Dibbern, Goles, Hirschheim, \& Jayatilaka, 2004), e-business (e.g., Pavlou \& Chai, 2002), organizational behavior (e.g., Higgins, Duxbury, \& Irving, 1992), marketing (e.g., Reinartz, Krafft, \& Hoyer, 2004), and consumer behavior (e.g., Fornell \& Robinson, 1983). Since 1987, for instance, more than 20 studies using PLS have been published in five top-tier marketing journals (Eggert, 2007) - the majority in

\footnotetext{
New Challenges to International Marketing Advances in International Marketing, Volume 20, 277-319 Copyright $(C) 2009$ by Emerald Group Publishing Limited All rights of reproduction in any form reserved ISSN: 1474-7979/doi:10.1108/S1474-7979(2009)0000020014
} 
the last six years. PLS is the method of choice for success factor studies in marketing (Albers, 2009) and for estimating the various national customer satisfaction index models (e.g., Fornell, 1992). The PLS methodology has also achieved an increasingly popular role in empirical research in international marketing, which may represent an appreciation of distinctive methodological features of PLS. As of March 2008, more than 30 articles on international marketing using PLS were published in double-blind reviewed journals. However, these publications show a rather large variability in the way how PLS is applied and how its outcomes are reported. In many instances, the rationale for choosing PLS among a possible set of alternative analytical techniques is not made explicit.

Although several articles offer guidance for the use of covariance-based structural equation modeling (CBSEM) in international marketing (e.g., Steenkamp \& Baumgartner, 1998; Malhotra, 2001; Iacobucci, Grisaffe, Duhachek, \& Marcati, 2003), there are no similar subject-specific guidelines for the use of PLS. While there are general recommendations for the use of PLS (e.g., Hulland, 1999), the specific requirements and typical research problems of international marketing have not been addressed yet. Our main aims are to shed light on PLS path modeling as an SEM technique, to reveal the strengths and weaknesses of PLS in general, and to deliver guidelines for its use in international marketing in particular.

\section{APPLICATIONS OF PLS PATH MODELING IN INTERNATIONAL MARKETING}

In order to determine the status quo of PLS path modeling in international marketing research, we conducted an exhaustive literature review. An evaluation of double-blind reviewed journals through important academic publishing databases (e.g., ABI/Inform, Elsevier ScienceDirect, Emerald Insight, Google Scholar, PsycINFO, Swetswise) revealed that more than 30 academic articles in the domain of international marketing (in a broad sense) used PLS path modeling as means of statistical analysis. We assessed what the main motivation for the use of PLS was in respect of each article. Moreover, we checked for applications of PLS in combination with one or more additional methods, and whether the main reason for conducting any additional method(s) was mentioned.

Table 1 lists all the identified academic articles that use PLS as a method of analysis in the context of international marketing. Green and Ryans 
Table 1. Studies Using PLS Path Modeling in International Marketing Research.

\begin{tabular}{|c|c|c|c|}
\hline Study & Motivation for Using PLS Path Modeling & Additional Analysis & $\begin{array}{c}\text { Reason for } \\
\text { Additional Analysis }\end{array}$ \\
\hline Acedo and Jones (2007, JWB) & $\begin{array}{l}\text { "The PLS technique is justified where theory is insufficiently grounded } \\
\text { and the variables or measures do not conform to a rigorously } \\
\text { specified measurement model, or fit a certain distribution" (p. 242) }\end{array}$ & $t$-test & Group comparison \\
\hline $\begin{array}{l}\text { Ainuddin, Beamish, Hulland, } \\
\text { and Rouse (2007, JWB) }\end{array}$ & $\begin{array}{l}\text { "Use of PLS is especially suited to exploratory studies such as this, } \\
\text { where the measures }[\ldots] \text { are new and the relationships }[\ldots] \text { have not } \\
\text { been previously tested" (p. 56) }\end{array}$ & $\mathrm{N} / \mathrm{A}$ & $\mathrm{N} / \mathrm{A}$ \\
\hline $\begin{array}{l}\text { Alpert, Kamins, Sakano, } \\
\text { Onzo, and Graham } \\
\text { (2001, IMR) }\end{array}$ & $\begin{array}{l}\text { "Formative indicators can only be analyzed using partial least squares } \\
\text { (PLS), and not by using the more common structural equation } \\
\text { technique of LISREL" (p. 177-178) }\end{array}$ & $\begin{array}{l}\text { Multiple regression } \\
\text { and Chow test }\end{array}$ & Group comparison \\
\hline $\begin{array}{l}\text { Birkinshaw, Morrison, and } \\
\text { Hulland (1995, SMJ) }\end{array}$ & $\begin{array}{l}\text { "PLS is most appropriate when sample sizes are small, when } \\
\text { assumptions of multivariate normality and interval scaled data } \\
\text { cannot be made, and when the researcher is primarily concerned with } \\
\text { prediction of the dependent variable" (pp. 646-647) }\end{array}$ & Multiple regression & Analysis of subgroups \\
\hline $\begin{array}{l}\text { Calantone, Graham, and } \\
\text { Mintu-Wimsatt } \\
(1998, \text { IJRM) }\end{array}$ & $\begin{array}{l}\text { "The PLS parameter estimates better reveal the strength and direction } \\
\text { (i.e., positive vs. negative) of the relationships among variables } \\
\text { compared to correlation coefficients" (p. 28), "PLS avoids } \\
\text { parameters estimation biases common in regression analysis" (p. 28) }\end{array}$ & LISREL & Path significances \\
\hline $\begin{array}{l}\text { Festge and Schwaiger } \\
\qquad(2007, \text { AIM })\end{array}$ & $\begin{array}{l}\text { "The researcher's focus is placed on the explanation of an endogenous } \\
\text { construct" (p. 192) }\end{array}$ & Logistic regression & $\begin{array}{l}\text { Verify model for } \\
\text { binary variables }\end{array}$ \\
\hline $\begin{array}{l}\text { Gerpott and Jakopin } \\
\quad(2005, \text { SBR })\end{array}$ & Not explicitly mentioned & $\mathrm{N} / \mathrm{A}$ & $\mathrm{N} / \mathrm{A}$ \\
\hline $\begin{array}{l}\text { Graham, Mintu, and Rodgers } \\
\text { (1994, Mgmt.Sc.) }\end{array}$ & $\begin{array}{l}\text { "Parameters can be estimated independent of sample size" (p. 79), } \\
\text { "PLS avoids parameter estimation biases inherent in regression } \\
\text { analysis" (p. 80), "PLS provides the most flexibility regarding } \\
\text { measurement of the constructs" (p. } 80 \text { ) }\end{array}$ & LISREL & $\begin{array}{l}\text { In order to test path } \\
\text { significances }\end{array}$ \\
\hline Green and Ryans (1990, JPIM) & $\begin{array}{l}\text { "Given that the purpose of this study is to predict [...], PLS has thus } \\
\text { been chosen as the structural equation modeling approach" (p. 53), } \\
\text { "[PLS] is more robust with small sample sizes" (p. 53), "the data do } \\
\text { not have to be multivariate normal because of the fixed point } \\
\text { estimation" (p. 53) }\end{array}$ & $\mathrm{N} / \mathrm{A}$ & $\mathrm{N} / \mathrm{A}$ \\
\hline $\begin{array}{l}\text { Holzmüller and Stöttinger } \\
\quad(1996, \text { JIM })\end{array}$ & Not explicitly mentioned & $\mathrm{N} / \mathrm{A}$ & $\mathrm{N} / \mathrm{A}$ \\
\hline
\end{tabular}


Holzmüller and Kasper (1991, MIR)

Inkpen and Birkenshaw

$$
\text { (1994, IBR) }
$$

Johansson and Yip

$$
\text { (1994, SMJ) }
$$

Johnson, Herrmann, and Gustafsson (2002, JEP)

Julien and Ramangalahy (2003, ETP)

Lee, Yang, and Graham (2006, JIBS)

Lee (2001, JBR)

Lee (2000, EJM)

Mahmood, Bagchi, and Ford (2004, IJEC)
"Fewer restrictive assumptions," "ratio between sample size and the number of parameters to be estimated," "exploratory intention" (p. 58)

"All relationships are modeled simultaneously, eliminating concerns about multicollinearity" (p. 208)

"Less stringent assumptions about the randomness of the sample and the normality of the distribution of variables" (p. 587), "smaller sample sizes, as each causal subsystem sequence of paths is estimated separately" (p. 587)

Not explicitly mentioned

"PLS is known to be particularly advantageous in the initial development and assessment phase of theory building," "the PLS method is $[\ldots]$ more robust since its does not require either a large sample or normally distributed data" (p. 233)

"PLS [...] is more appropriate for the exploratory nature of [a] study," "[PLS] allows for formative indicators $[\ldots]$ and dichotomous constructs" (p. 632)

"PLS [...] can accommodate a small sample size" (p. 153)

"PLS avoids many of the restrictive assumptions imposed by other causal models that involve latent variables such as LISREL", "PLS provides measurement assessment", "A jack-knife procedure [...] generates an approximate $t$-statistic. This overcomes the disadvantage of the lack of formal significance tests for parameters resulting from non-parametric methods", "PLS enables the explicit estimation of the multiple item construct, which affords a comparison of [groups] at the construct level" (p. 196)

"The PLS technique imposes minimal demand on measurement scales, sample sizes, and residual distributions. [It] is often used to test and validate exploratory models" (p. 20)
N/A

$\mathrm{N} / \mathrm{A}$

$\mathrm{N} / \mathrm{A}$

$\mathrm{N} / \mathrm{A}$

$\mathrm{N} / \mathrm{A}$

$\mathrm{N} / \mathrm{A}$

N/A

$\mathrm{N} / \mathrm{A}$

$\mathrm{N} / \mathrm{A}$

$t$-test and ANOVA

Group comparison

Confirmatory factor analysis

$t$-test and ANOVA

\section{Examine}

unidimensionality

Group comparison

AMOS

Fit statistics 
Mintu-Wimsatt and Graham (2004, JAMS)

Money (2004, JBR)

Money and Graham (1999, JIBS)

Nakamura, Shaver, and Yeung (1996, IJIO)

Nijssen and Douglas

(2008, JIM)

O'Cass and Fenech (2003,

EJM

Pavlou and Chai (2002, JECR)

Pullman, Granzin, and Olsen (1997, IBR)

Pinto, Rodríguez Escudero, and Gutíerrez Cillán (2008, IMM)

Singh, Fassott, Chao, and Hoffmann (2006a, IMR) Singh, Fassott, Zhao, and Boughton (2006b, JCB)

Stöttinger and Holzmüller (2001, MIR)

Tsang (2002, SMJ)

Venaik, Midgley, and Devinney (2005, JIBS)
"PLS is a more rigorous approach [...] compared to correlation and regression analyses" (p. 351), "PLS [...] avoids small sample size problems," "PLS minimizes biases associated with [...

dichotomous and ordinal measures" (p. 352)

In order to validate regression results

$\mathrm{N} / \mathrm{A}$

Not explicitly mentioned

"PLS can deal effectively with formative scales, is distribution free, and is a powerful instrument for analyzing small samples" (p. 95)

"[PLS] circumvent[s] the necessity for the multivariate normal assumption" (p. 377)

"PLS allows [...] a simultaneous analysis of both whether the hypothesized relationships at the theoretical level are empirically acceptable, and also how well the measures relate to each construct," "[t]he ability to include multiple measures for each construct," "the nature of [...] measures," "the small sample size" (p. 246)

"The objective of PLS is explanation of the relationships and prediction of the criterion variables of the model" (p. 221)

"Avoiding any distributional assumption of the observed variables" (p. 160), "the sample size required in PLS is much smaller" (p. 160), "PLS can handle both types of measurement models, reflective and formative" (p. 160)

"PLS [...] uses distribution-free assumptions, [...] especially when independence of observations is not stipulated" (p. 89)

Not explicitly mentioned

Not explicitly mentioned

"PLS is particularly suitable for data analysis during the early stage of theory development where the theoretical model and its measures are not well formed" (p. 841)

"At an early stage of development [...] the regression based approach of PLS is considered more appropriate than covariance-based methods such as LISREL," applicable when a multivariate normal distribution can not be assured, small sample size in combination with a complex model including second-order constructs, formative indicators (p. 665)
$\mathrm{N} / \mathrm{A}$

$\mathrm{N} / \mathrm{A}$

$\mathrm{N} / \mathrm{A}$

LISREL Regression \&

Chow Test

$\mathrm{N} / \mathrm{A}$

$\mathrm{N} / \mathrm{A}$

Path significances

group comparison

$\mathrm{N} / \mathrm{A}$

$\mathrm{N} / \mathrm{A}$

N/A

N/A

$\mathrm{N} / \mathrm{A}$

$\mathrm{N} / \mathrm{A}$

$\mathrm{N} / \mathrm{A}$

N/A

N/A

$\mathrm{N} / \mathrm{A}$

N/A

N/A

$\mathrm{N} / \mathrm{A}$

$\mathrm{N} / \mathrm{A}$

N/A

N/A

$t$-test

Group comparison

N/A

$\mathrm{N} / \mathrm{A}$ 
(1990) published the first study using PLS in international marketing. Although there were several articles in the 1990s, the popularity of PLS seems to have largely increased in the new millennium. Journals that published PLS applications in the international marketing domain are (journal abbreviation and number of studies in parentheses):

- Advances in International Marketing (AIM; 1)

- Entrepreneurship Theory and Practice (ETP; 1)

- European Journal of Marketing (EJM; 2)

- Industrial Marketing Management (IMM; 1)

- International Business Review (IBR; 2)

- International Journal of Electronic Commerce (IJEC; 1)

- International Journal of Industrial Organization (IJIO; 1)

- International Journal of Research in Marketing (IJRM; 1)

- International Marketing Review (IMR; 2)

- Journal of Business Research (JBR; 2)

- Journal of Consumer Behaviour (JCR; 1)

- Journal of Economic Psychology (JEP; 1)

- Journal of Electronic Commerce Research (JECR; 1)

- Journal of International Business Studies (JIBS; 3)

- Journal of International Marketing (JIM; 2)

- Journal of Product Innovation Management (JPIM; 1)

- Journal of the Academy of Marketing Science (JAMS; 1)

- Journal of World Business (JWB; 2)

- Management International Review (MIR;2)

- Management Science (Mgmt.Sc.; 1)

- Schmalenbach Business Review (SBR; 1)

- Strategic Management Journal (SMJ; 3)

Our first analysis of these 33 studies provides some evidence of the increasing popularity of PLS path modeling within the research community. The analysis also points to the authors' motivation for the use of this particular statistical method. Many researchers argue that the goal of their studies is in line with particular strengths of PLS path modeling. The most important motivations are exploration and prediction, as PLS path modeling is recommended in an early stage of theoretical development in order to test and validate exploratory models. Another powerful feature of PLS path modeling is that it is suitable for prediction-oriented research. Thereby, the methodology assists researchers who focus on the explanation of endogenous constructs. The characteristics of PLS path modeling, which 
researchers regard as relevant for their studies on international marketing, can be summarized as follows:

- PLS delivers latent variable scores, i.e. proxies of the constructs, which are measured by one or several indicators (manifest variables).

- PLS path modeling avoids small sample size problems and can therefore be applied in some situations when other methods cannot.

- PLS path modeling can estimate very complex models with many latent and manifest variables.

- PLS path modeling has less stringent assumptions about the distribution of variables and error terms.

- PLS can handle both reflective and formative measurement models.

However, there are several arguments regarding the characteristics of PLS path modeling that should be treated with caution: PLS path modeling does not have less stringent assumptions about the representativeness of the sample. Sometimes, PLS path modeling is implicitly presumed to be the only method that can cope with formative indicators (cf. Chin, 1998); however, LISREL also has this ability (cf. Jarvis, MacKenzie, \& Podsakoff, 2003). Although comparisons of methods provide some evidence of PLS' favorable behavior in light of multicollinearity (cf. Gustafsson \& Johnson, 2004), PLS does not resist multicollinearity. Since PLS determines measurement models (in Mode B) as well as structural models by means of multiple regressions, PLS estimates can be subject to multicollinearity problems, too.

Our review furthermore discloses that some studies use PLS path modeling in combination with other analysis techniques such as $t$-tests, ANOVA, and CBSEM. Yet, these methods are not always a suitable choice. If, for instance, PLS was selected because of its distribution-free character, it would be inconsequent to introduce distributional assumptions in another analysis such as $t$-test or ANOVA, or to rely on criteria derived from CBSEM's chi-square statistic. This finding provides evidence that either PLS path modeling lacks important features, which makes the use of additional analyses necessary, or that researchers are not aware of the respective extensions of PLS path modeling. In particular, the findings underpin the strong need for a PLS-based approach to multigroup analysis (MGA) in international marketing in order to compare model parameters across groups such as countries or cultures.

The remainder of this chapter is organized as follows: In the following Section 2, we describe the working principle of PLS path modeling and discuss the characteristics of PLS in detail in order to assist research of 
international marketing to distinguish between facts and fiction about PLS path modeling. Section 3 addresses the assessment of PLS path modeling results, which represents a key area of concern when applying the methodology. Five issues are covered: Sections 3.1 and 3.2 provide an overview of the use of PLS path modeling for the assessment of reflective and formative measurement models, respectively. Section 3.3 presents the available criteria for evaluating the structural model. Section 3.4 presents and discusses the use of bootstrapping for determining confidence intervals and the significance of PLS path modeling estimates. As a courtesy to international marketing's need to compare model parameters across countries, Section 3.5 proposes a new PLS-based approach for group comparisons based on bootstrapping. Finally, Section 4 sums up the key findings and draws conclusions.

\section{PLS PATH MODELING}

PLS is a family of alternating least squares algorithms, or "prescriptions," which extend principal component and canonical correlation analysis. The method was designed by Wold $(1974,1982,1985)$ for the analysis of high dimensional data in a low-structure environment and has undergone various extensions and modifications. This chapter builds on Wold's (1982) basic algorithmic design and some extensions developed by Lohmöller (1989).

\subsection{The Nature of PLS Path Models}

PLS path models are formally defined by two sets of linear equations: the inner model and the outer model. The inner model specifies the relationships between unobserved or latent variables, whereas the outer model specifies the relationships between a latent variable and its observed or manifest variables. The various literatures do not always employ the same terminology. For instance, publications addressing CBSEM (e.g., Rigdon, 1998) often refer to structural models and measurement models or (observed) indicator variables; whereas those focusing on PLS path modeling (e.g., Lohmöller, 1989) use the terms inner model and outer model or manifest variables for similar elements of the causal model. Fig. 1 depicts an example of a PLS path model.

In order to simplify the notation of the model and in line with conventional descriptions of PLS, we assume that latent and manifest variables are 


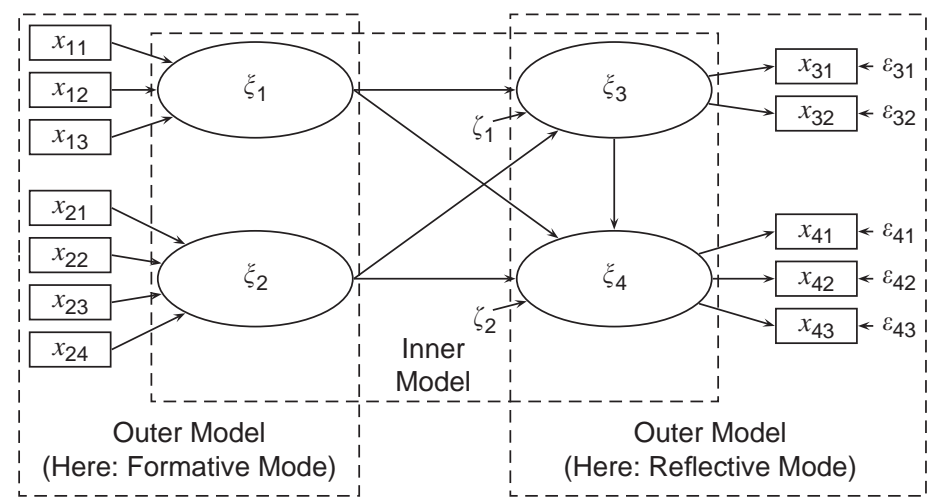

Fig. 1. Example of a PLS Path Model.

standardized so that the location parameters can be discarded in the following equations. The inner model for relationships between latent variables can be written as:

$$
\xi=B \xi+\zeta
$$

where $\xi$ is the vector of latent variables, $B$ denotes the matrix of coefficients of their relationships, and $\zeta$ represents the inner model residuals. The basic PLS design assumes a recursive inner model that is subject to predictor specification. Thus, the inner model constitutes a causal chain system (i.e. with uncorrelated residuals and without correlations between the residual term of a certain endogenous latent variable and its explanatory latent variables). Predictor specification reduces Eq. (1) to:

$$
(\xi \mid \xi)=B \xi
$$

PLS path modeling includes two different kinds of outer models: reflective (Mode A) and formative (Mode B) measurement models. The selection of a certain outer mode is subject to theoretical reasoning (Diamantopoulos \& Winklhofer, 2001).

The reflective mode has causal relationships from the latent variable to the manifest variables in its block. Thus, each manifest variable in a certain measurement model is assumed to be generated as a linear function of its latent variables and the residual $\varepsilon$ :

$$
X_{x}=\Lambda_{x} \xi+\varepsilon_{x}
$$


where $\Lambda$ represents the loading (pattern) coefficients. The outer relationships are also subject to predictor specification - implying that there are no correlations between the outer residuals and the latent variable of the same block - that reduces Eq. (3) to:

$$
\left(X_{x} \mid \xi\right)=\Lambda_{x} \xi
$$

The formative mode of a measurement model has causal relationships from the manifest variables to the latent variable. For those blocks, the linear relationships are given as follows:

$$
\xi=\Pi_{x} X_{x}+\varepsilon_{x}
$$

In the formative mode, predictor specification is also in effect, reducing Eq. (5) to:

$$
\left(\xi \mid X_{x}\right)=\Pi_{x} X_{x}
$$

Moreover, it is important to see that the terms "formative" and "reflective," as well as the connotation which is associated with the classification of "causal" and "effect," point at a difference between the characterization of the latent variable measurement models' mode. Although a latent variable was originally considered an exact linear combination of its indicators for formative indicator specifications, a causal indicator specification - the original term for these indicators - may be more general in that it holds both in the case of an exact linear combination, as well as when the indicators do not completely determine the latent variable (Bollen, 1989). In this chapter, we consistently use the terms "formative" and "reflective" measurement models - in the way they are described, for example, by Jarvis et al. (2003). It must be noted, though, that while we use the terms "reflective" and "formative" constructs to refer to latent variables that are measured with reflective or formative indicators, "strictly speaking, it is the (observable) measures (i.e. the indicators) that are being modeled as reflective or formative and not the (unobservable) constructs as such" (Diamantopoulos, 2006, p. 15). The following section introduces the basic PLS algorithm, which starts with the data matrix of manifest variables and successively computes the latent variable scores and all unknown relationships. 


\subsection{The PLS Path Modeling Algorithm}

The PLS algorithm is essentially a sequence of regressions in terms of weight vectors. The weight vectors obtained at convergence satisfy fixed point equations (see Dijkstra, 2009, for a general analysis of such equations and ensuing convergence issues). The basic PLS algorithm, as suggested by Lohmöller (1989), includes the following three stages:

Stage 1: Iterative estimation of latent variable scores, consisting of a four-step iterative procedure that is repeated until convergence is obtained:

(1) outer approximation of the latent variable scores,

(2) estimation of the inner weights,

(3) inner approximation of the latent variable scores, and

(4) estimation of the outer weights.

Stage 2: Estimation of outer weights/loading and path coefficients.

Stage 3: Estimation of location parameters.

We draw on Tenenhaus, Esposito Vinzi, Chatelin, and Lauro's (2005) description of the first stage of the PLS path modeling algorithm:

Step 1: Outer approximation of the latent variable scores. Outer proxies of the latent variables, $\hat{\xi}_{n}^{\text {outer }}$, are calculated as linear combinations of their respective indicators. These outer proxies are standardized; i.e. they have a mean of 0 and a standard deviation of 1 . The weights of the linear combinations result from step 4 of the previous iteration. When the algorithm is initialized, and no weights are available yet, any arbitrary nontrivial linear combination of indicators can serve as an outer proxy of a latent variable.

Step 2: Estimation of the inner weights. Inner weights are calculated for each latent variable in order to reflect how strongly the other latent variables are connected to it. There are three schemes available for determining the inner weights. Wold (1982) originally proposed the centroid scheme. Later, Lohmöller (1989) developed the factor weighting and path weighting schemes. The centroid scheme uses the sign of the correlations between a latent variable - or, more precisely, the outer proxy - and its adjacent latent variables; the factor weighting scheme uses the correlations. The path weighting scheme pays tribute to the arrow orientations in the path model. The weights of those latent variables that explain the focal latent variable are set to the regression coefficients stemming from a regression of the focal latent variable (regressant) on its latent repressor variables. The weights of those latent variables, which are explained by the focal latent 
variable, are determined in a similar manner as in the factor weighting scheme. Regardless of the weighting scheme, a weight of zero is assigned to all nonadjacent latent variables.

Step 3: Inner approximation of the latent variable scores. Inner proxies of the latent variables, $\hat{\xi}_{n}^{\text {inner }}$, are calculated as linear combinations of the outer proxies of their respective adjacent latent variables, using the aforedetermined inner weights.

Step 4: Estimation of the outer weights. The outer weights are calculated either as the covariances between the inner proxy of each latent variable and its indicators (in Mode A, reflective), or as the regression weights resulting from the ordinary least squares regression of the inner proxy of each latent variable on its indicators (in Mode B, formative).

These four steps are repeated until the change in outer weights between two iterations drops below a predefined limit. The algorithm terminates after step 1, delivering latent variable scores for all latent variables. Loadings and inner regression coefficients are then calculated in a straightforward way, given the constructed indices and using Eqs. (4) and (5). In order to determine the path coefficients, for each endogenous latent variable a (multiple) linear regression is conducted.

\subsection{Methodological Characteristics}

Methodological literature on PLS path modeling or publications on causal modeling applications that utilize the PLS path modeling approach usually refer to certain advantageous features of this technique (e.g., Fornell \& Bookstein, 1982; Jöreskog \& Wold, 1982; Dijkstra, 1983; Lohmöller, 1989; Schneeweiß, 1991; Falk \& Miller, 1992). The popularity of PLS path modeling among scientists and practitioners is rooted in four genuine characteristics: First, instead of solely drawing on the common reflective mode, the PLS path modeling algorithm allows the unrestricted computation of cause-effect relationship models that employ both reflective and formative measurement models (Diamantopoulos \& Winklhofer, 2001). Second, PLS can be used to estimate path models when sample sizes are small (Chin \& Newsted, 1999). Third, PLS path models can be very complex (i.e. consist of many latent and manifest variables) without leading to estimation problems (Wold, 1985). PLS path modeling is methodologically advantageous to CBSEM whenever improper or nonconvergent results are likely to occur (i.e. Heywood cases; see Krijnen, Dijkstra, \& Gill, 1998). 
Furthermore, with more complex models, the number of latent and manifest variables may be high in relation to the number of observations. Fourth, PLS path modeling can be used when distributions are highly skewed (Bagozzi, 1994), or the independence of observations is not assured, because, as Fornell (1982, p. 443) has argued, "there are no distributional requirements." All four characteristics are discussed in detail.

\subsubsection{Reflective and Formative Measurement Models}

Structural equation models usually involve latent variables with multiple indicators. The measurement model or outer model specifies the relationship between indicators and latent variables. The direction of path relationships per measurement model and, thus, the causality between the latent variable and its indicators are either described by a reflective or a formative mode. The reflective measurement model has its roots in classical test theory and psychometrics (Nunnally \& Bernstein, 1994). Each indicator represents an error-afflicted measurement of the latent variable. The direction of causality is from the construct to the indicators; thus, observed measures are assumed to reflect variation in the latent variable. In other words, changes in the construct are expected to be manifested in changes in all of its indicators. Fig. 2 provides an example of a reflective measurement model.

In some situations, for instance in the early stages of model development, it is appropriate to determine causality from the measures to the construct, rather than vice versa (Blalock, 1971). This kind of situation represents a formative measurement model, which is adequate when a construct is defined as a combination of its indicators. A typical example would be marketing mix elements that are determined by a combination of variables (Fornell, 1982) and, hence, have to be modeled as a (typically linear)

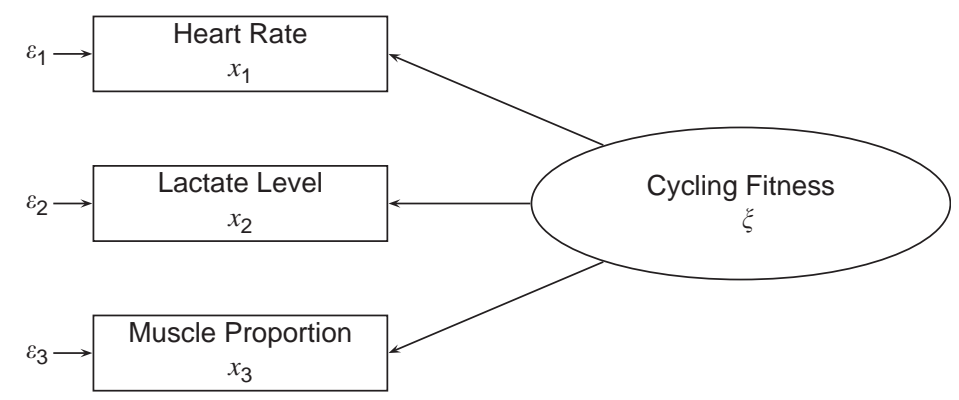

Fig. 2. Example of a Reflective Measurement Model. 


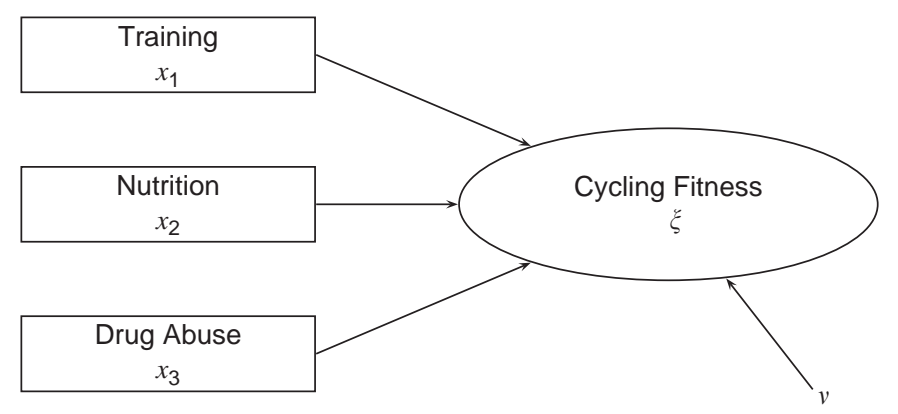

Fig. 3. Example of a Formative Measurement Model.

combination of its indicators plus a disturbance term (Diamantopoulos, 2006). Consequently, the latent variable is defined as a weighted score across all representative indicator variables, with each variable embodying an independent dimension in its own right. An increase in the value of one indicator translates into a higher score for the composite variable, regardless of the value of the other indicators. The formative measurement model exhausts the entire domain of the index, meaning that the indicators collectively represent all the relevant dimensions or independent underpinnings of the latent variable. One implication of this direction of causality is that omitting one indicator could omit a unique part of the formative measurement model and change the meaning of the variable (Diamantopoulos \& Winklhofer, 2001). Fig. 3 presents an example of a formative measurement model.

Although the inclusion of formative measures in CBSEM has been well documented (e.g., Jöreskog \& Goldberger, 1975; MacCallum \& Browne, 1993; Jöreskog \& Sörbom, 1996), analysts usually encounter identification problems. As a sort of ad-hoc remedy, formative indicators could be modeled in CBSEM by re-specifying the formative indicators as exogenous latent variables with single indicators, fixed unit loadings, and a fixed measurement error (Williams, Edwards, \& Vandenberg, 2003). In contrast, similar problems do not arise in PLS path modeling. The PLS path modeling algorithm - as it is presented in Section 2.2 - is equally well suited for SEM with reflective and/or formative measurement models. The only problematic issue, however, is connected to manifest variables' critical level of multicollinearity in formative measurement models.

Researchers should carefully decide whether a measurement model shall be formative or reflective. Measurement model misspecification is an often observed phenomenon. According to Jarvis et al. (2003), 28\% of top-level 
marketing articles use misspecified measurement models in SEM applications. A substantial number of latent variables in these studies were inappropriately specified by treating formative measurement models as if they were reflective. Misspecification of measurement models can bias inner model parameter estimation and lead to incorrect assessments of relationships (Jarvis et al., 2003). The decision to use either formative or reflective indicators for a construct should be based on the nature of the causal relationship between the indicators and the latent variables in the measurement model (Bollen, 1989). The most suitable approach to avoid misspecification of measurement models in SEM is to consider the conceptual discussion of the differences between formative and reflective measurement models by, e.g., Howell, Breivik, and Wilcox (2000a, 2007b); Bagozzi (2007); Bollen (2007); Bollen and Lennox (1991); Diamantopoulos and Winklhofer (2001); Edwards and Bagozzi (2000), as well as the C-OAR-SE procedure (Rossiter, 2002) and the design rules for determining the specific type of measurement model put forward by Jarvis et al. (2003). Notwithstanding this theoretic foundation, there are only a few endeavors in the academic business literature that stress statistical techniques for the assessment of formative measurement models in PLS path models. For instance, Bollen and Ting's (1993) confirmatory tetrad analysis (CTA) results are used in SEM (e.g., Bollen \& Ting, 2000) to assess whether manifest variables in the measurement model are independent determinants of a latent variable rather than its reflections in an effect indicator scale. Gudergan, Ringle, Wende, and Will (2008) show that PLS path modeling assumptions are consistent with the CTA procedure and, thereby, provide a more rigorous foundation for evaluating whether or not empirical data support a reflective indicator specification rather than a formative indicator specification.

\subsubsection{Sample Size}

The sample size argument has its roots in the considerable obstacles faced when conducting CBSEM with small samples. A substantial number of simulation studies on CBSEM compare alternative discrepancy functions and their estimation bias, accuracy, and robustness with respect to sample size. Boomsma and Hoogland (2001), for example, conclude that there are nonconvergence problems and improper CBSEM solutions in small samples (e.g., 200 or fewer cases). These authors provide evidence that CBSEM - depending on the selected discrepancy function and the model complexity - requires several hundred or even thousands of observations. 
In contrast, the sample size can be considerably smaller in PLS path modeling. For example, "there can be more variables than observations and there may be a small amount of data that are missing completely at random" (Tenenhaus et al., 2005, p. 202). Wold (1989) illustrates the low sample size requirement by analyzing a path model based on a data set consisting of 10 observations and 27 manifest variables. A rule of thumb for robust PLS path modeling estimations suggests that the sample size be equal to the larger of the following (Barclay, Higgins, \& Thompson, 1995): (1) ten times the number of indicators of the scale with the largest number of formative indicators, or (2) ten times the largest number of structural paths directed at a particular construct in the inner path model. Chin and Newsted (1999) present a Monte Carlo simulation study on PLS with small samples. They find that the PLS path modeling approach can provide information about the appropriateness of indicators at sample size as low as 20. This study confirms the consistency at large on loading estimates with increased numbers of observations and numbers of manifest variables per measurement model.

As a result of these peculiarities, researchers and practitioners use PLS path modeling, instead of CBSEM, when the sample size is relatively low. However, this persistent belief in publications and research that support the claim that PLS is more efficient at small sample size is inadvertently misleading the research community as it asks for accuracy instead of statistical power. Goodhue, Lewis, and Thompson (2006, p. 9) argue that statistical significance is a primary consideration and accuracy a secondary one: "without statistical significance, accuracy contributes no scientific knowledge." Their findings suggest that PLS does not have an advantage in terms of detecting statistical significance in small sample sizes. Furthermore, Goodhue et al. (2006) find no evidence that PLS with bootstrapping provides more statistical power than CBSEM with small sample sizes. The generally accepted ten times rule of thumb for the minimum sample size in PLS analyses can lead to unacceptably low levels of statistical power. It is only in the case of a strong effect size (and high reliability) that rule of thumb may lead to acceptable power. However, the authors provide strong evidence that the ten-times-rule does not take into account effect size, reliability, the number of indicators, or other factors which are known to affect power. Thus, the recommendations on acceptable PLS sample size might be misleading.

The choice of an appropriate sample size depends on more than the magnitude of the relationship or the desired level of power. It is evident that "a researcher must consider the distributional characteristics of the data, 
potential missing data, the psychometric properties of the variables examined, and the magnitude of the relationships considered before deciding on an appropriate sample size to use or to ensure that a sufficient sample size is actually available to study the phenomena of interest" (Marcoulides \& Saunders, 2006, p. VI). Marcoulides and Saunders offer other warnings that clearly echo those presented in the CBSEM literature. For instance, Schneeweiß (2001) addresses the magnitude of standard errors in PLS path modeling estimators resulting from not using enough observations (consistency) and indicators for each latent variable (consistency at large). This research provides closed form equations to determine the magnitude of finite item bias relative to the number of indicators used in a model. Schneeweiß $(2001$, p. 310$)$ indicates that item bias is generally small when reflective measurement models involve many indicators, "each with a sizable loading and an error which is small and uncorrelated (or only slightly correlated) with other error variables."

Goodhue et al. (2006) stress that even though PLS path modeling seems to have no special abilities at small sample size, its performance, in terms of statistical power, is equal to other techniques for normally distributed data. In their view, PLS path modeling is still a convenient and powerful technique that is appropriate for many research situations such as complex research models with sample sizes that would be too small for CBSEM techniques. They therefore note that "[u]nfortunately PLS does not provide researchers with a magic bullet for achieving adequate statistical power at small sample sizes" (Goodhue et al., 2006, p. 10). In a similar vain, Marcoulides and Saunders (2006, p. VIII) state that "PLS is not a silver bullet to be used with samples of any size!" Thus, researchers must ensure that the sample size is large enough to support the conclusions - the PLSrelated rule of thumb might work well in some instances, but in others it might fail miserably.

\subsubsection{Model Complexity}

Some CBSEM discrepancy functions (e.g., GFI and AGFI) decline as model complexity increases (i.e. more observed variables or more constructs), and they may be inappropriate for more complex models (Anderson \& Gerbing, 1984). For example, Boomsma and Hoogland (2001) experimentally varied the model complexity (number of estimated parameters) and the number of degrees of freedom and found that the more parameters to be estimated, the more nonconvergence and improper solutions will occur, or - from an information point of view - the larger the estimation requirements, the more information is needed. However, sample size has a primary effect: With 
increasing numbers of observations, there is a decreasing occurrence of nonconvergence and improper solutions. According to these authors' simulation study results, if the sample size and the factor loadings are about the same, more complications are expected regarding nonconvergence and improper solutions as model complexity increases: "It was shown that answers to these questions are conditional on data and model characteristics alike. In practice, however, applied researchers often do not know the data and the model characteristics before data collection and analysis. In new areas of applied research, especially when measurement instruments are in a developing stage, little is known about distributional characteristics of observed variables. Also, in phases of model exploration there are uncertainties about the complexity of the "final models," about the number of reliable indicators and the size of factor loadings. It is evident that with better measurements and stronger theoretical foundations of model structures, it becomes much easier to make proper decisions on the choice of estimators and the planning of sample size" (Boomsma \& Hoogland, 2001, p. 22). This quote stresses the complementary character of PLS in respect of CBSEM in theory testing, especially with respect to the issues of model complexity when the model building proceeds from simple to more complex models. PLS is considered better suited to explain complex relationships (Fornell, 1982; Fornell, Lorange, \& Roos, 1990). Wold (1985, pp. 589-590) has therefore stated that "PLS comes to the fore in larger models, when the importance shifts from individual variables and parameters to packages of variables and aggregate parameters. [...] In large, complex models with latent variables PLS is virtually without competition." Moreover, the PLS algorithm allows for a considerable increase in model complexity and, hence, a noticeable reduction in the distance between subject matter analysis and statistical technique in domains with continuous access to reliable data.

\subsubsection{On the Robustness of Parameter Estimates}

Although several authors argue that the PLS path modeling approach offers certain advantages when compared to covariance-based methods (Chin, 1998; Fornell, 1982), others provide notes of caution on the subject of this discussion (Marcoulides \& Saunders, 2006). However, literature on the formal comparison of CBSEM and PLS is rare (cf. Dijkstra, 1983; McDonald, 1996). Only few simulation studies analyze the parameter estimations of both methodologies, thereby uncovering certain peculiarities regarding their behavior in applications. Researchers and practitioners require this information when selecting an appropriate means for estimating a particular SEM with their collected data. 
A primary Monte Carlo simulation study by Vilares, Almeida, and Coelho (2009) analyzes the effects of two assumptions on the performance of CBSEM and PLS: the symmetry of the distribution and the reflective modeling of the indicators. These authors compare both methods' performance when these assumptions hold and when they are violated; for instance, when the distribution of the observations is skewed and some indicators follow a formative scheme. In their base model (reflective model with symmetric data), the quality of the two estimation methods is very similar, especially for the estimation of outer loadings. The Vilares et al. (2009) study sustains the phenomenon of outer loading overestimation by PLS and more conservative outcomes for inner path model relationships, whereas the Maximum Likelihood (ML) method shows exactly the opposite tendency, with overestimation of the path coefficients and a general underestimation of the indicator loadings. However, when a formative latent variable is introduced, the PLS method demonstrates higher robustness compared to CBSEM. The same kind of finding holds with skewed data results. Accordingly, the authors conclude that in case of skewed data, PLS estimates are better than ML estimates, in terms of both bias and precision. The ML estimators seem to be more sensitive to the various potential deficiencies in the data and model specification.

The research by Vilares et al. (2009) analyzes formative measurement models in that it draws on reflective loadings results, thus depicting a situation of measurement model misspecification (Jarvis et al., 2003). Another Monte Carlo simulation study by Ringle, Wilson, and Götz (2007) compares the performance of CBSEM and PLS for formative exogenous latent variables in a causal model. Both methodologies provide estimates for the simulated sets of data that are very close to the population parameters when averaged. Although CBSEM estimates in the formative measurement and the structural model significantly decrease in accuracy and robustness in respect of nonnormal data, the performance of reflective measurement models' estimations is not seriously affected by these changed data characteristics. Ringle et al. (2007) reveal similar results for PLS path modeling, but the decline in accuracy and robustness is considerably lower compared to CBSEM. On the basis of these findings, we can conclude that in the normal data scenario, CBSEM provides accurate and robust parameter estimates that are equal or superior in comparison to PLS estimates, no matter what measurement models are used. However, if the premises for the application of CBSEM are violated, such as regarding the required minimum number of observations for robust model estimations or the multivariate normality assumption for some CBSEM discrepancy 
functions, the PLS approach offers robust approximations. It must be noted though that, in general, PLS parameter estimates are less than optimal regarding bias and consistency. The estimates will be asymptotically correct under the condition of consistency at large, i.e. both a large sample size and large numbers of indicators per latent variable (Jöreskog \& Wold, 1982).

\subsubsection{Choice between the Covariance- and Variance-Based SEM Method}

Even though Wold (1974) developed the fixed-point estimation procedure for causal modeling as an alternative to CBSEM, the covariance-fitting-based SEM procedures (e.g., ML, GLS, ULS) and the variance-based PLS approach are complementary rather than competitive. According to Jöreskog (1982, p. 270) "ML is theory-oriented, and emphasizes the transition from exploratory to confirmatory analysis. PLS is primarily intended for causalpredictive analysis in situations of high complexity but low theoretical information." The philosophical distinction between these approaches is whether to use CBSEM for theory testing and development, or PLS path modeling for predictive applications. As visualized in Fig. 4, in causal modeling situations where prior theory is strong and further testing and development is the goal, CBSEM is the most appropriate statistical methodology. Yet, due to the indeterminacy of factor score estimations, there is a loss of predictive accuracy. This occurrence, of course, is not of concern in theory testing where structural relationships (i.e. parameter estimation) between concepts is of primary concern. Moreover, hypothesis building and the assessment of CBSEM results through global goodness-of-fit

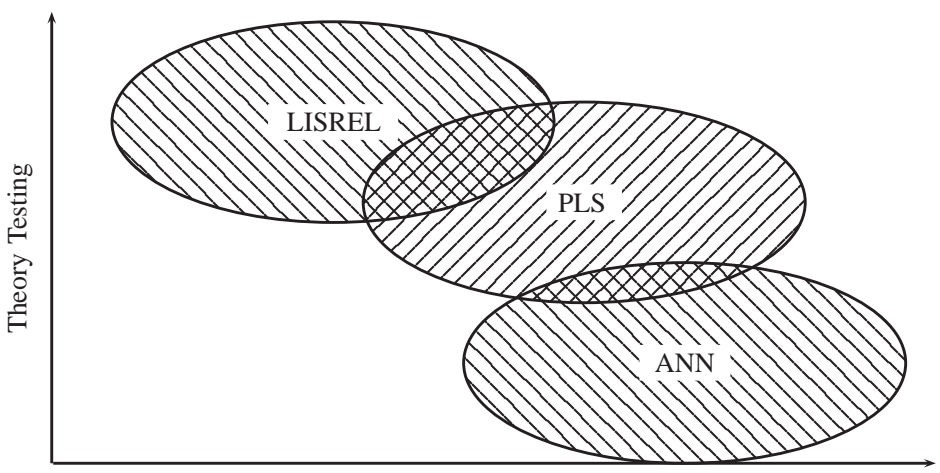

Prediction

Fig. 4. Purpose of the Analysis. 
criteria further emphasizes the theory-testing, rather than theory-building, character of this methodology (Anderson \& Gerbing, 1988).

In research settings with predictive scope, weak theory, and no need for an understanding of underlying relationships, artificial neural networks (ANN) may be useful. This approach creates artificial neurons and their interrelations in the hidden layer that connects the input and output data, in order, for example, to improve predictivity without necessarily creating a model of theoretical meaning. Yet, Hsu, Chen, and Hsieh (2006) find that their ANN-based SEM technique is similar to PLS path modeling.

Using the iterative estimation technique as described in Section 3.2, the PLS path modeling approach calculates latent variable scores as exact linear combinations of the observed measures. Thereby, the approach avoids the indeterminacy problem and provides an exact definition of component scores (Fornell, 1982). The PLS approach is adequate for causal modeling applications whose purpose is prediction and/or theory building. Although PLS path modeling can be used for theory confirmation, it assumes that all measured variance is useful for explanation in applications (e.g., Sarkar, Echambadi, Cavusgil, \& Aulakh, 2001) and indicates the causal relationships with significant effect. Thus, parameter estimates are obtained based on the ability to minimize the residual variances of dependent variables (both latent and observed variables). An assessment of these PLS estimation outcomes - for example, by standard errors that are obtained through bootstrapping (see Section 3.4) - builds on the evaluation of partial path model structures. PLS' lack of a global optimization function and consequently measures of global goodness of model fit definitely limits the use of PLS for theory testing.

A researcher must arrive at a decision on the causal model analysis with latent variables in order to select an appropriate statistical technique. Instead of using the model to explain the covariation among all indicators, which is the objective of CBSEM, PLS path modeling maximizes the explained variance of all dependent variables and, thus, supports predictionoriented goals. Although the CBSEM and PLS path modeling methodologies differ from a statistical point of view, PLS estimates may represent good proxies of the CBSEM results. If CBSEM premises are violated, such as distributional assumptions, minimum sample size, or maximum model complexity, and related methodological matters arise, such as Heywood cases, an inability to converge to a solution, parameters that are outside reasonable limits, and large standard errors regarding parameter estimates (Rindskopf, 1984), PLS path modeling may represent a reasonable methodological alternative for theory testing. 


\section{EVALUATION OF PLS PATH MODEL RESULTS}

PLS path modeling does not provide any global goodness-of-fit criterion. As a consequence, Chin (1998) has put forward a catalog of criteria to assess partial model structures. A systematic application of these criteria is a two-step process, encompassing (1) the assessment of the outer model and (2) the assessment of the inner model. Fig. 5 depicts this two-step process.

At the beginning of the two step process, model assessment focuses on the measurement models. A systematic evaluation of PLS estimates reveals the measurement reliability and validity according to certain criteria that are associated with formative and reflective outer model. It only makes sense to evaluate the inner path model estimates when the calculated latent variable scores show evidence of sufficient reliability and validity.

\subsection{Assessing Reflective Measurement Models}

Reflective measurement models should be assessed with regard to their reliability and validity. Usually, the first criterion which is checked is internal consistency reliability. The traditional criterion for internal consistency is Cronbach's $\alpha$ (Cronbach, 1951), which provides an estimate for the reliability based on the indicator intercorrelations. While Cronbach's

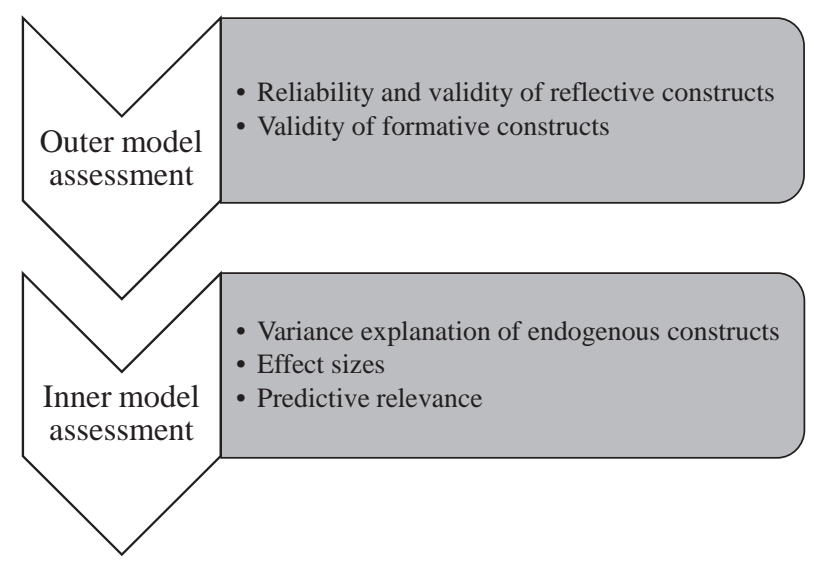

Fig. 5. A Two-Step Process of PLS Path Model Assessment. 
$\alpha$ assumes that all indicators are equally reliable, PLS prioritizes indicators according to their reliability, resulting in a more reliable composite. As Cronbach's $\alpha$ tends to provide a severe underestimation of the internal consistency reliability of latent variables in PLS path models, it is more appropriate to apply a different measure, the composite reliability $\rho_{c}$ (Werts, Linn, \& Jöreskog, 1974). The composite reliability takes into account that indicators have different loadings, and can be interpreted in the same way as Cronbach's $\alpha$. No matter which particular reliability coefficient is used, an internal consistency reliability value above 0.7 in early stages of research and values above 0.8 or 0.9 in more advanced stages of research are regarded as satisfactory (Nunnally \& Bernstein, 1994), whereas a value below 0.6 indicates a lack of reliability.

As the reliability of indicators varies, the reliability of each indicator should be assessed. Researchers postulate that a latent variable should explain a substantial part of each indicator's variance (usually at least 50\%). Accordingly, the absolute correlations between a construct and each of its manifest variables (i.e. the absolute standardized outer loadings) should be higher than $0.7(\approx \sqrt{0.5})$. Moreover, some psychometrists (e.g., Churchill, 1979) recommend eliminating reflective indicators from measurement models if their outer standardized loadings are smaller than 0.4. Taking into account PLS' characteristic of consistency at large, one should be careful when eliminating indicators. Only if an indicator's reliability is low and eliminating this indicator goes along with a substantial increase of composite reliability, it makes sense to discard this indicator.

For the assessment of validity, two validity subtypes are usually examined: the convergent validity and the discriminant validity. Convergent validity signifies that a set of indicators represents one and the same underlying construct, which can be demonstrated through their unidimensionality. Fornell and Larcker (1981) suggest using the average variance extracted (AVE) as a criterion of convergent validity. An AVE value of at least 0.5 indicates sufficient convergent validity, meaning that a latent variable is able to explain more than half of the variance of its indicators on average (e.g., Götz, Liehr-Gobbers, \& Krafft, 2009). Discriminant validity is a rather complementary concept: Two conceptually different concepts should exhibit sufficient difference (i.e. the joint set of indicators is expected not to be unidimensional). In PLS path modeling, two measures of discriminant validity have been put forward: The Fornell-Larcker criterion and the crossloadings. The Fornell-Larcker criterion (Fornell \& Larcker, 1981) postulates that a latent variable shares more variance with its assigned indicators than with any other latent variable. In statistical terms, the AVE of each latent 
Table 2. Assessing Reflective Measurement Models.

\begin{tabular}{|c|c|}
\hline Criterion & Description \\
\hline $\begin{array}{l}\text { Composite reliability } \\
\quad\left(\rho_{c}\right)\end{array}$ & $\begin{array}{l}\rho_{c}=\left(\sum \lambda_{i}\right)^{2} /\left[\left(\sum \lambda_{i}\right)^{2}+\sum \operatorname{Var}\left(\varepsilon_{i}\right)\right], \text { where } \lambda_{i} \text { is the outer } \\
\quad \text { (component) loading to an indicator, and } \operatorname{Var}\left(\varepsilon_{i}\right)=1-\lambda_{i}^{2} \text { in } \\
\text { case of standardized indicators. The composite reliability is a } \\
\text { measure of internal consistency and must not be lower than } 0.6 \text {. }\end{array}$ \\
\hline Indicator reliability & $\begin{array}{l}\text { Absolute standardized outer (component) loadings should be } \\
\text { higher than } 0.7 \text {. }\end{array}$ \\
\hline $\begin{array}{l}\text { Average variance } \\
\text { extracted (AVE) }\end{array}$ & $\begin{array}{l}\mathrm{AVE}=\left(\sum \lambda_{i}^{2}\right) /\left[\sum \lambda_{i}^{2}+\sum \operatorname{Var}\left(\varepsilon_{i}\right)\right], \text { where } \lambda_{i} \text { is the component } \\
\text { loading to an indicator and } \operatorname{Var}\left(\varepsilon_{i}\right)=1-\lambda_{i}^{2} \text { in case of } \\
\text { standardized indicators. The average variance extracted should } \\
\text { be higher than } 0.5 .\end{array}$ \\
\hline $\begin{array}{l}\text { Fornell-Larcker } \\
\text { criterion }\end{array}$ & $\begin{array}{l}\text { In order to ensure discriminant validity, the AVE of each latent } \\
\text { variable should be higher than the squared correlations with all } \\
\text { other latent variables. Thereby, each latent variable shares more } \\
\text { variance with its own block of indicators than with another } \\
\text { latent variable representing a different block of indicators. }\end{array}$ \\
\hline Cross-loadings & $\begin{array}{l}\text { Cross-loadings offer another check for discriminant validity. If an } \\
\text { indicator has a higher correlation with another latent variable } \\
\text { than with its respective latent variable, the appropriateness of } \\
\text { the model should be reconsidered. }\end{array}$ \\
\hline
\end{tabular}

variable should be greater than the latent variable's highest squared correlation with any other latent variable. The second criterion of discriminant validity is usually a bit more liberal: The loading of each indicator is expected to be greater than all of its cross-loadings (Chin, 1998; Götz et al., 2009). Although the Fornell-Larcker criterion assesses discriminant validity on the construct level, the cross-loadings allow this kind of evaluation on the indicator level.

In summary, a reliable and valid reflective measurement of latent variables should meet all the criteria as listed in Table 2. If this is not the case, the researcher may want to exclude single indicators from a specific measurement model and eventually revise the path model.

\subsection{Assessing Formative Measurement Models}

Bollen (1989) and Bagozzi (1994) emphasize that traditional validity assessments and classical test theory do not apply to manifest variables that are used in formative measurement models and that the concepts of reliability (i.e. internal consistency) and construct validity (i.e. convergent 
and discriminant validity) are not meaningful when a formative mode is employed. It is the assumption of error-free measures that renders the question of indicator reliability irrelevant. Diamantopoulos (2006, p. 11) concludes in respect of formative measurement that "reliability becomes an irrelevant criterion for assessing measurement quality." The less important reliability becomes, the more pivotal it is to secure validity. A first examination of the validity of formative indicators should use theoretic rationale and expert opinion (Rossiter, 2002). A second assessment of the validity of formative constructs should consist of statistical analyses on two levels: the construct level and the indicator level.

At the construct level, the question arises as to whether the formative index indeed carries the intended meaning. A first check could be the nomological validity: Does the formative index behave within a net of hypotheses as expected? Those relationships between the formative index and other constructs in the path model that are sufficiently referred to in prior research should be strong and significant. Moreover, researchers should be concerned about the construct's error-term $v$, which represents the part of the construct that is not captured by any indicator. In order to estimate the size of this error, one can assess the external validity by means of regressing the formative index on a reflective measure of the same construct. The variance of the error $v$ can be determined as follows:

$$
\operatorname{Var}(v)=1-\frac{\gamma^{2}}{\operatorname{rel}(\xi)}
$$

Here, $\xi$ stands for the reflective measure of the focal construct and $\gamma$ for the correlation between the formative and the reflective measure of the same construct, which is equal to the standardized regression coefficient. The ratio of the equation includes a correction of the imperfect reliability of the reflective measure. The external validity can finally be calculated as $1-\operatorname{Var}(v)$. The current literature does not provide any recommendations for thresholds of external validity. We suggest a value of 0.8 as a minimum for external validity, which would mean that the formative index carries about $80 \%$ of the intended meaning. However, researchers should always take into account the particularities of their research fields and eventually ask for a higher external validity.

At the indicator level, the question arises as to whether each indicator indeed delivers a contribution to the formative index by carrying the intended meaning. Besides face and content validity, which can both be assessed a priori, some statistical evaluations can be conducted a posteriori. 
There are two cases in which researchers should critically examine whether a particular indicator should enter into the index or not. An indicator can be irrelevant for the construction of the formative index because it either does not have a significant impact on the formative index, or because it exhibits high multicollinearity, which could mean that the indicator's information is redundant. In order to check for the first case, the significance of the estimated indicator weights can be determined by means of bootstrapping (cf. Davison \& Hinkley, 2003; Chin, 1998; Tenenhaus et al., 2005, and see Section 3.4). In order to check for the second case, researchers should assess the degree of multicollinearity among the formative indicators (Diamantopoulos \& Winklhofer, 2001; Cassel, Hackl, \& Westlund, 2000, Grewal, Cote, \& Baumgartner, 2004), for instance, by calculating the variance inflation factor (VIF) or the tolerance values. A rule of thumb from econometrics states that VIFs greater than 10 reveal a critical level of multicollinearity. However, any VIF substantially greater than 1 indicates multicollinearity and should alert researchers to the typical problems of multicollinearity.

The different steps and criteria for assessing the validity of formative indices are summarized in Table 3. A final note of caution: formative indicators should never be discarded simply on the basis of statistical outcomes. Such actions may substantially change the content of the formative index (Jarvis et al., 2003). Thus, the researcher should keep both significant and insignificant formative indicators in the measurement model as long as this is conceptually justified. Usually, PLS structural model

Table 3. Assessing Formative Measurement Models.

\begin{tabular}{|c|c|}
\hline Criterion & Description \\
\hline Nomological validity & $\begin{array}{l}\text { The relationships between the formative index and other } \\
\text { constructs in the path model, which are sufficiently well } \\
\text { known through prior research, should be strong and } \\
\text { significant. }\end{array}$ \\
\hline External validity & $\begin{array}{l}\text { The formative index should explain a big part of the variance of } \\
\text { an alternative reflective measure of the focal construct. }\end{array}$ \\
\hline Significance of weights & $\begin{array}{l}\text { Estimated weights of formative measurement models should be } \\
\text { significant. }\end{array}$ \\
\hline Multicollinearity & $\begin{array}{l}\text { Manifest variables in a formative block should be tested for } \\
\text { multicollinearity. The variance inflation factor (VIF) can be } \\
\text { used for such tests. As a rule of thumb, a VIF greater than ten } \\
\text { indicates the presence of harmful collinearity. However, any } \\
\text { VIF substantially greater than one indicates multicollinearity. }\end{array}$ \\
\hline
\end{tabular}


estimates hardly alter after performing an elimination of insignificant or highly collinear formative indicators, providing further support for the decision to retain such indicators in the PLS path model. In the case of multicollinearity, indicator weight estimates can be distorted. This fact requires researchers to be particularly cautious when interpreting indicator weights as a sign of indicator importance.

\subsection{Assessing the Structural Model}

Reliable and valid outer model estimations permit an evaluation of the inner path model estimates. Table 4 provides an overview of the typical criteria. The essential criterion for this assessment is the coefficient of determination $\left(R^{2}\right)$ of the endogenous latent variables. Chin (1998) describes $R^{2}$ values of 0.67, 0.33, and 0.19 in PLS path models as substantial, moderate, and weak, respectively. If certain inner path model structures explain a endogenous latent variable by only a few (e.g., one or two) exogenous latent variables, "moderate" $R^{2}$ may be acceptable. However, if the endogenous latent variable relies on several exogenous latent variables, the $R^{2}$ value should exhibit at least a substantial level. Lower results, on the contrary, cast

Table 4. Assessing Structural Models.

\begin{tabular}{|c|c|}
\hline Criterion & Description \\
\hline $\begin{array}{l}R^{2} \text { of endogenous } \\
\text { latent variables }\end{array}$ & $\begin{array}{l}R^{2} \text { values of } 0.67,0.33 \text {, or } 0.19 \text { for endogenous latent variables in the } \\
\text { inner path model are described as substantial, moderate, or weak by } \\
\text { Chin }(1998, \text { p. } 323) \text {. }\end{array}$ \\
\hline $\begin{array}{l}\text { Estimates for path } \\
\text { coefficients }\end{array}$ & $\begin{array}{l}\text { The estimated values for path relationships in the structural model } \\
\text { should be evaluated in terms of sign, magnitude, and significance } \\
\text { (the latter via bootstrapping). }\end{array}$ \\
\hline Effect size $f^{2}$ & $\begin{array}{l}f^{2}=\left(R_{\text {included }}^{2}-R_{\text {excluded }}^{2}\right) /\left(1-R_{\text {included }}^{2}\right) \text {; values of } 0.02,0.15 \text {, and } 0.35 \\
\text { can be viewed as a gauge for whether a predictor latent variable has } \\
\text { a weak, medium, or large effect at the structural level. }\end{array}$ \\
\hline $\begin{array}{l}\text { Prediction relevance } \\
\qquad\left(Q^{2} \text { and } q^{2}\right)\end{array}$ & $\begin{array}{l}\text { The } Q^{2} \text { is calculated based on the blindfolding procedure: } \\
Q^{2}=1-\left(\sum_{D} \mathrm{SSE}_{D}\right) /\left(\sum_{D} \mathrm{SSO}_{D}\right) . D \text { is the omission distance, SSE is } \\
\text { the sum of squares of prediction errors, and SSO is the sum of } \\
\text { squares of observations. } Q^{2} \text {-values above zero give evidence that the } \\
\text { observed values are well reconstructed and that the model has } \\
\text { predictive relevance }\left(Q^{2} \text {-values below zero indicate a lack of }\right. \\
\text { predictive relevance). In correspondence to } f^{2} \text {, the relative impact of } \\
\text { the structural model on the observed measures for latent dependent } \\
\text { variables can be assessed: } q^{2}=\left(Q_{\text {included }}^{2}-Q_{\text {excluded }}^{2}\right) /\left(1-Q_{\text {included }}^{2}\right) \text {. }\end{array}$ \\
\hline
\end{tabular}


doubts regarding the theoretical underpinnings and demonstrate that the model is incapable to explain the endogenous latent variable(s).

The individual path coefficients of the PLS structural model can be interpreted as standardized beta coefficients of ordinary least squares regressions. Structural paths, whose sign is in keeping with a priori postulated algebraic signs, provide a partial empirical validation of the theoretically assumed relationships between latent variables. Paths that possess an algebraic sign contrary to expectations do not support the a priori formed hypotheses. In order to determine the confidence intervals of the path coefficients and statistical inference, resampling techniques such as bootstrapping should be used (cf. Tenenhaus et al., 2005, and see Section 3.4). Another important evaluation of direct and indirect relationships of the predecessor of a certain endogenous latent variable involves the analysis of mediating (Helm, Eggert, \& Garnefeld, 2009) and moderating effects (Henseler \& Fassott, 2009). Researchers and practitioners using PLS path modeling should first assess their hypothesized path model of direct effects and then conduct additional analyses involving mediating and moderating effects to learn, for instance, more about possible spurious effects or suppressor effects.

Albers (2009) proposes a new paradigm for success factor studies in marketing. The significance of highly plausible direct inner path model relationships is no longer of interest to researchers and practitioners. Rather, the sum of the direct effect and all indirect effects of a particular latent variable on another (the total effect) should be the subject of evaluation for further interpretation. This new paradigm copes with a frequent observation in PLS path modeling that the standardized inner path model coefficients decline with an increased number of indirect relationships, especially when mediating latent variables have a suppressor effect on the direct path. Consequently, considerable direct relationships may become insignificant after including additional indirect relationships. In such instances, the total effect should remain at a relatively constant, sizeable level and thus provide more reasonable grounds for conclusions on the inner path model relationships.

For each effect in the path model, one can evaluate the effect size by means of Cohen's (1988) $f^{2}$. The effect size $f^{2}$ is calculated as the increase in $R^{2}$ relative to the proportion of variance of the endogenous latent variable that remains unexplained. According to Cohen (1988), $f^{2}$ values of 0.02 , 0.15 , and 0.35 signify small, medium, and large effects, respectively.

Another assessment of the structural model involves the model's capability to predict. The predominant measure of predictive relevance is 
Stone-Geisser's $Q^{2}$ (Stone, 1974; Geisser, 1975), which can be measured using blindfolding procedures (Tenenhaus et al., 2005). The Stone-Geisser criterion postulates that the model must be able to provide a prediction of the endogenous latent variable's indicators. The technique represents a synthesis of function fitting and cross-validation. As Chin (1998) points out, "the prediction of observables or potential observables is of much greater relevance than the estimator of what are often artificial construct-parameters" (p. 320). Wold (1982) argues that the sample reuse technique - especially the blindfolding procedure to obtain the crossvalidated redundancy (instead of the cross-validated communality) - fits the PLS path modeling approach like "hand in glove."

The blindfolding procedure is only applied to endogenous latent variables that have a reflective measurement model operationalization. If this value for a certain endogenous latent variable is larger than zero, its explanatory variables provide predictive relevance. In analogy to the effect-size $f^{2}$ evaluation, the relative impact of the predictive relevance can be assessed by means of the measure $q^{2}$ : values of $0.02,0.15$, and 0.35 reveal a small, medium, or large predictive relevance of a certain latent variable, thus explaining the endogenous latent variable under evaluation.

\subsection{Bootstrapping}

The nonparametric bootstrap (Davison \& Hinkley, 2003; Efron \& Tibshirani, 1993) procedure can be used in PLS path modeling to provide confidence intervals for all parameter estimates, building the basis for statistical inference. In general, the bootstrap technique provides an estimate of the shape, spread, and bias of the sampling distribution of a specific statistic. Bootstrapping treats the observed sample as if it represents the population. The procedure creates a large, pre-specified number of bootstrap samples (e.g., 5,000). Each bootstrap sample should have the same number of cases as the original sample. Bootstrap samples are created by randomly drawing cases with replacement from the original sample.

PLS estimates the path model for each bootstrap sample. The obtained path model coefficients form a bootstrap distribution, which can be viewed as an approximation of the sampling distribution. The bootstrapping analysis allows for the statistical testing of the hypothesis $H_{0}: w=0$ ( $w$ can be any parameter estimated by PLS) against the alternative hypothesis $H_{1}$ : $w \neq 0$ at $m+n-2$ degrees of freedom (where $m$ is the number of PLS estimates for $w$ in the original sample, which is $1 ; n$ is the number of 
bootstrap estimates for $w$, e.g., 5,000). The PLS results for all bootstrap samples provide the mean value and standard error for each path model coefficient. This information permits a student's $t$-test to be performed for the significance of path model relationships. Chin (1998) proposes using the following test statistic for PLS:

$$
t_{\mathrm{emp}}=\frac{w}{s e(w)}
$$

whereby $t_{\mathrm{emp}}$ represents the empirical $t$-value, $w$ the original PLS estimate of a certain path coefficient, and $s e(w)$ its bootstrapping standard error. The student's $t$-distribution table provides the critical $t$-value at given $\alpha$-levels and the respective number of degrees of freedom.

Instead of just reporting the significance of a parameter, it would be more valuable to report the confidence interval. If a confidence interval for an estimated path coefficient $w$ does not include zero, the hypothesis that $w$ equals zero is rejected. Testing with confidence intervals is advantageous, as it provides more information about the estimate of $w$. Shaffer (1995, p. 575) remarks that "if the hypothesis is not rejected, the power of the procedure can be gauged by the width of the interval."

In order to determine the confidence interval of a model parameter, say a path coefficient, one has to recognize that the bootstrapping procedure generates a distribution $T$ of $w$. However, significance testing needs to account for the distribution of $T$ under $H_{0}$, which is the null distribution of $T$. This distribution is essential for performing the test since it provides the basis for determining the $p$-value. If the null distribution is unknown, the asymptotic normality of the test statistic is commonly assumed. Although nonparametric alternatives can be obtained through bootstrapping, this approach overlooks the possibility that the data could be generated under the alternative hypothesis $H_{1}: \theta \neq \theta_{0}$.

This problem can be addressed by examining the statistical correspondence between tests of significance and confidence intervals when the null hypothesis concerns a particular parameter value (Gudergan et al., 2008). Bootstrapping confidence intervals are well established (Efron \& Tibshirani, 1993; Davison \& Hinkley, 2003). If the bootstrap estimates of bias and variance are denoted by $b_{B}$ and $v_{B}$, then the corresponding approximate $1-\alpha$ (two-tailed) confidence interval is:

$$
t-b_{B} \pm v_{B}^{1 / 2} z_{1-\alpha / 2}
$$

where $b_{B}=\bar{w}_{B}-w$, the difference of the mean value of $w$ for all bootstraps and the original PLS estimation of that path coefficient. A null hypothesis 
$H_{0}: w=0$ is accepted (or rejected) at a given level $\alpha$, if the corresponding $(1-\alpha)$ confidence interval includes (or does not include) the parameter value $\theta_{0}$. The bias-corrected bootstrap confidence interval in Eq. (9) provides a basis to account for the aforementioned problem and, thus, can be used as an appropriate means to test the significance of PLS-estimated path coefficients (Gudergan et al., 2008).

In PLS path modeling, the latent variable scores may have different signs if, for examples, estimation $A$ uses an alternative outer weights initialization of the algorithm (say, $+L V_{1}$ ) compared with estimation $B$ (in this case, $\left.-L V_{2}\right)$. Still, the absolute $L V$-values of both estimations usually represent equivalent solutions, i.e. $\left|+L V_{1}\right|=\left|-L V_{2}\right|$ (for a discussion on this sign indeterminacy of PLS see Wold, 1985). This sign indeterminacy of PLS latent variable scores may also result in arbitrary sign changes during the bootstrap path model estimations. Such occurrence of sign changes "pull" the mean value of bootstrapping results (e.g., for parameter $w$ ) toward zero and, thereby, bias the bootstrap standard error upward. Arbitrary sign changes systematically reduce the value of $t_{\mathrm{emp}}$ and, thus, the possibility of the rejection of $H_{0}$ at a given $\alpha$ level. The standard error of estimates increases dramatically without any real meaning if the sign changes are not properly taken into account (Tenenhaus et al., 2005). Rather than not treating sign changes in the bootstrapping results, we suggest using the individual sign change option. The working principle is as follows: If a PLS path coefficient estimation for a bootstrap subsample shows a different sign compared with the original path model estimation, the procedure reverses the sign of that path coefficient in the bootstrapping subsample. Thus, the signs in the outer and inner models of each resample are made consistent with the signs in the original sample in order to avoid these sign-changerelated problems.

\subsection{Group Comparisons and Other Advances in PLS Analyses}

A threat to the validity of SEM results may lie in the heterogeneity of observations. The level of observed or unobserved heterogeneity can lead to spurious or suppressor effects, and generally to misinterpretations. Typically, researchers in international marketing are well aware of the heterogeneity of observations; that is, different population parameters are likely for different subpopulations such as countries or cultures. Although cross-cultural or cross-national differences are related to observed heterogeneity, there can also be unobserved heterogeneity, which cannot be attributed to any 
predetermined variable. Similar to ignoring observed heterogeneity due to countries or cultures, unobserved heterogeneity represents a serious problem in respect of interpreting PLS results (Ringle, 2006).

Our review of PLS path modeling applications in international marketing gives a mixed picture regarding the examination of heterogeneity. Although a significant number of studies take observed heterogeneity into account by means of multigroup comparisons, none of the studies accounts for unobserved heterogeneity. However, there are several PLS-based approaches to detect unobserved heterogeneity. Analytical techniques such as finite mixture partial least squares (FIMIX-PLS; Hahn, Johnson, Herrmann, \& Huber, 2002; Ringle, Sarstedt, \& Mooi, 2009a; Ringle, Wende, \& Will, 2009b) or the recently developed PLS typological alternatives (e.g., Esposito Vinzi, Ringle, Squillacciotti, \& Trinchera, 2007; Ringle \& Schlittgen, 2007) are becoming mandatory for evaluating PLS path modeling results. Using these techniques, researchers can either confirm that their results are not distorted by unobserved heterogeneity or identify thus far neglected variables that describe the uncovered data segments.

As soon as conceptual deliberations or methods such as FIMIX-PLS suggest different models for different subgroups, PLS-based multigroup analysis (MGA) should be conducted. In MGA, a population parameter $\beta$ is hypothesized to differ for two subpopulations: $\beta^{(1)} \neq \beta^{(2)}$. Referring to PLS path modeling, researchers would for instance ask whether one could conclude differences in population parameters from the differences in path coefficients.

The primary approach for group comparisons is a $t$-test, as described by Keil et al. (2000). These authors suggest using the standard errors obtained from bootstrapping as the input for a parametric test. After having exposed the subsamples to separate bootstrap analyses and having made parametric assumptions about the distributions of the parameter standard errors, one can calculate the following statistic for the difference in paths between groups (Keil et al., 2000):

$$
t=\frac{b^{(1)}-b^{(2)}}{\sqrt{\frac{\left(n^{(1)}-1\right)^{2}}{n^{(1)}+n^{(2)}-2} \operatorname{se}\left(b^{(1)}\right)^{2}+\frac{\left(n^{(2)}-1\right)^{2}}{n^{(1)}+n^{(2)}-2} \operatorname{se}\left(b^{(2)}\right)^{2}} \sqrt{\frac{1}{n^{(1)}}+\frac{1}{n^{(2)}}}}
$$

This statistic is asymptotically $t$-distributed with $n^{(1)}+n^{(2)}-2$ degrees of freedom. The subsample-specific path coefficients are denoted as $b$, the sizes of the subsamples as $n$, and the path coefficient standard errors as resulting from bootstrapping as se. 
Chin and Dibbern (2009) cast doubt on whether this approach of multigroup comparison with its inherent distributional assumptions fits to PLS path modeling, which is generally regarded as being distribution-free. In line with these doubts, we present an alternative approach to PLS-based group comparisons that does not rely on distributional assumptions, as initially proposed by Henseler (2007). The working principle of the novel PLS-MGA approach is as follows: First, the subsamples to be compared are exposed to separate bootstrap analyses, and the bootstrap outcomes serve as a basis for the hypothesis tests of group differences. Instead of relying on distributional assumptions, the new approach evaluates the observed distribution of the bootstrap outcomes. Given two subsamples with parameter estimates (e.g., a path coefficient), $b^{(1)}$ and $b^{(2)}$, the conditional probability $P\left(b^{(1)}>b^{(2)} \mid \beta^{(1)} \leq \beta^{(2)}\right)$ has to be determined. Here, $\beta^{(1)}$ and $\beta^{(2)}$ represent the true population parameters of population 1 and 2 . A researcher would like to be sure that $P$ is below a specified $\alpha$-level before concluding that $\beta^{(1)}$ is greater than $\beta^{(2)}$.

If researchers know the parameter estimates of two subsamples from bootstrapping, they can easily verify how probable a difference in parameters between two subpopulations is and hence test their hypothesis with the following equation:

$$
P\left(b^{(1)}>b^{(2)} \mid \beta^{(1)} \leq \beta^{(2)}\right)=1-\sum_{\forall j, i} \frac{\Theta\left(2 \bar{b}^{(1)}-b_{j}^{(1)}-2 \bar{b}^{(2)}+b_{i}^{(2)}\right)}{J^{2}}
$$

In this equation, $J$ denotes the number of bootstrap samples, $b_{j}^{(1)}$ and $b_{i}^{(2)}$ the bootstrap parameter estimates, $\bar{b}^{-(1)}$ and $\bar{b}^{(2)}$ the means of the focal parameters over the bootstrap samples, and $\Theta$ the unit step function, which has a value of 1 if its argument exceeds 0 , otherwise 0 . The superscript in parentheses marks the respective group. This equation states that $J^{2}$ (i.e. all possible) comparisons of bootstrap parameters have to be made. In fact, this approach can be seen as a Mann-Whitney-Wilcoxon test (Wilcoxon, 1947; Mann \& Whitney, 1947) applied to the bootstrap-values corrected for the original parameter values.

PLS-MGA does not require any distributional assumptions and is simple to apply by using the bootstrap outputs that are generated by the prevailing PLS implementations such as SmartPLS (Ringle, Wende, \& Will, 2005). The way of determining the probability whether a population parameter differs across two sub-populations is unique to this new approach. Researchers can easily conduct the final calculations with available spreadsheet software such as MS Excel (a sample spreadsheet can be obtained from the first author). 
Besides the aforementioned methodological advances for addressing the requirement to capture unobserved heterogeneity, recent developments in the evaluation of PLS path modeling results focus on the problem of measurement model misspecification. Bucic and Gudergan (2004) use a PLS application to demonstrate the significant consequences of misspecification for path model estimates. The seven criteria that have been put forward by Jarvis et al. (2003) permit an a priori examination of the outer mode. In addition, a confirmatory tetrad measurement model analysis of PLS (CTA-PLS; Gudergan et al., 2008) provides a statistical test to evaluate the outer measurement model a posteriori.

Statistical support is there for specifying not only the measurement model but also the structural model. Research by Marcoulides (2003) and Wilson, Callaghan, Ringle, and Henseler (2007) addresses the inner path model specification search to uncover superior structures and more appropriate inner relationship directions.

Additional advances on the subject of evaluating path modeling results involve the development of global goodness-of-fit criteria. The PLS goodness-of-fit proposal by Tenenhaus et al. (2005) is the geometric mean of the average communalities (outer measurement model) and the average $R^{2}$ of endogenous latent variables, and is normed between 0 and 1 , where a higher value represents better path model estimations. However, while this criterion has only been applied in few applications (e.g., Esposito Vinzi et al., 2007) and has not been systematically analyzed in simulation studies, it is restricted to reflective outer models and may be subject to systematic improvement by means of path model modifications/manipulations. Future developments in this line of research may combine PLS and ML CBSEM global goodness-of-fit criteria. This procedure is well established in CBSEM for the asymptotic distribution-free estimators (ADF), which-like PLSdoes not follow distributional assumptions that allow the global goodnessof-fit to be computed. Consequently, researchers and practitioners should note the substantial link between CBSEM and PLS path modeling for which the literature has called over the last decades.

\section{SUMMARY AND CONCLUSION}

In international marketing research, both CBSEM and PLS provide a powerful framework for estimating causal models with latent variables and systems of simultaneous equations with measurement errors. CBSEM and PLS path modeling constitute two complementary, yet distinctive, 
statistical techniques for estimating parameters of conceptual models. A critical review of the PLS application in international marketing reveals that this methodology has increased in popularity, especially for multigroup analyses of PLS results for different nations. Our paper illustrates the PLS path modeling methodology and typical criteria for the assessment of results. Moreover, we introduce several advances in evaluating PLS model estimations, such as a novel approach for multigroup comparison (PLS-MGA).

PLS is based on least squares estimation with the primary objective being to maximize the explanation of variance in a structural equation model's dependent constructs. Jöreskog and Wold (1982, p. 270) suggest that "PLS is primarily intended for causal-predictive analysis in situations of high complexity but low theoretical information". In contrast, the primary measures used in CBSEM are overall goodness-of-fit measures that assess how well the hypothesized model fits the observed data. The model estimation is theory-oriented and emphasizes the confirmatory, rather than the exploratory, analysis. Consequently, in international marketing research, CBSEM should be used either to empirically confirm a system of hypotheses that underlie a causal model or to test and compare results for alternative theoretically established causal models. The prediction-oriented PLS method, on the contrary, does not require strong theory and can be used as a theory-building method (Gefen et al., 2000). PLS offers excellent capabilities for work with small samples and formative measurement, as the methodology is sufficient for most success factor (cause indicator) analyses in international marketing research. Moreover, complementary analytical techniques such as FIMIX-PLS for uncovering unobserved heterogeneity or multigroup PLS analysis may provide further differentiated path modeling results that allow for more precise interpretation. The review of PLS studies in international marketing reveals that few studies conduct multigroup analyses to identify differences in path coefficients across subgroups. No study has addressed the potentially serious problems of ignoring unobserved heterogeneity (Ringle, 2006). Owing to the severity of the consequences of neglecting unobserved heterogeneity, such additional analyses should become a standard means of evaluating PLS path modeling results, especially in international marketing research.

A final concern refers to the choice of SEM method. There may be situations in which CBSEM is preferable, in other situations PLS may be preferable. Moreover, there may be situations where using CBSEM is desirable but unobtainable, for example, due to violations in some key CBSEM assumptions (e.g., regarding sample size, distribution, and model 
identification); in such cases, PLS may provide a realistic alternative to CBSEM. Some authors also critically point out that both CBSEM and PLS follow the classical test theory paradigm, while especially for international marketing applications alternative methodologies following the probabilistic test theory may be advisable (Ewing, Salzberger, \& Sinkovics, 2005). All in all, the findings of our paper are deemed to help researchers in international marketing to adopt a more holistic perspective and to make informed decisions about the SEM method based on the nature and key objectives of their study.

\section{REFERENCES}

Acedo, F. J., \& Jones, M. V. (2007). Speed of internationalization and entrepreneurial cognition: Insights and a comparison between international new ventures, exporters and domestic firms. Journal of World Business, 42(3), 236-252.

Ainuddin, R. A., Beamish, P. W., Hulland, J. S., \& Rouse, M. J. (2007). Resource attributes and firm performance in international joint ventures. Journal of World Business, 42(1), 47-60.

Albers, S. (2009). PLS and success factor studies in marketing. In: V. Esposito Vinzi, W. W. Chin, J. Henseler \& H. Wang (Eds), Handbook of partial least squares: Concepts, methods, and applications. Berlin: Springer (in print).

Alpert, F., Kamins, M., Sakano, T., Onzo, N., \& Graham, J. (2001). Retail buyer beliefs, attitude, and behavior toward pioneer and me-too follower brands. International Marketing Review, 18(2), 160-187.

Anderson, J. C., \& Gerbing, D. W. (1984). The effect of sampling error on convergence, improper solutions, and goodness of fit indices for maximum likelihood confirmatory factor analysis. Psychometrika, 49(2), 155-173.

Anderson, J. C., \& Gerbing, D. W. (1988). Structural equation modeling in practice: A review and recommended two-step approach. Psychological Bulletin, 103(3), 411-423.

Bagozzi, R. P. (1994). In: Principles of marketing research (pp. 317-385). Oxford: Blackwell.

Bagozzi, R. P. (2007). On the meaning of formative measurement and how it differs from reflective measurement: Comment on Howell, Breivik, and Wilcox (2007). Psychological Methods, 12(2), 229-237.

Barclay, D. W., Higgins, C., \& Thompson, R. (1995). The partial least squares approach to causal modeling: Personal computer adoption and use as illustration. Technology Studies, 2(2), 285-309.

Birkinshaw, J., Morrison, A., \& Hulland, J. (1995). Structural and competitive determinants of a global integration strategy. Strategic Management Journal, 16(8), 637-655.

Blalock, H. M. (1971). Causal models in the social sciences. Chicago, IL: Aldine-Atherton.

Bollen, K. A. (1989). Structural equations with latent variables. New York, NY: Wiley.

Bollen, K. A. (2007). Interpretational confounding is due to misspecification, not to type of indicator: Comment on Howell, Breivik, and Wilcox (2007). Psychological Methods, 12(2), 219-228. 
Bollen, K. A., \& Lennox, R. (1991). Conventional wisdom on measurement: A structural equation perspective. Psychological Bulletin, 110(2), 305-314.

Bollen, K. A., \& Ting, K. (1993). Confirmatory tetrad analysis. Sociological Methodology, 23, $147-175$.

Bollen, K. A., \& Ting, K. (2000). A tetrad test for causal indicators. Psychological Methods, 5(1), 3-22.

Boomsma, A., \& Hoogland, J. J. (2001). The robustness of LISREL modeling revisited. In: R. Cudeck, S. du Toit \& D. Sörbom (Eds), Structural equation modeling: Present and future (pp. 139-168). Chicago, IL: Scientific Software International.

Bucic, T., \& Gudergan, S. P. (2004). The impact of organizational settings on creativity and learning in alliances. Management, 7(3), 257-273.

Calantone, R. J., Graham, J. L., \& Mintu-Wimsatt, A. (1998). Problem-solving approach in an international context: Antecedents and outcomes. International Journal of Research in Marketing, 15(1), 19-35.

Cassel, C. M., Hackl, P., \& Westlund, A. H. (2000). On measurement of intangible assets: A study of robustness of partial least squares. Total Quality Management, 11(7), 897-907.

Chin, W. W. (1998). The partial least squares approach to structural equation modeling. In: G. A. Marcoulides (Ed.), Modern Methods for Business Research (pp. 295-358). Mahwah, NJ: Lawrence Erlbaum Associates.

Chin, W. W., \& Dibbern, J. (2009). A permutation based procedure for multi-group (PLS) analysis: Results of tests of differences on simulated data. In: V. Esposito Vinzi, W. W. Chin, J. Henseler \& H. Wang (Eds), Handbook of partial least squares: Concepts, methods and applications in marketing and related fields. Springer (In press).

Chin, W. W., \& Newsted, P. R. (1999). Structural equation modeling analysis with small samples using partial least squares. In: R. H. Hoyle (Ed.), Statistical strategies for small sample research (pp. 307-342). Thousand Oaks, CA: Sage.

Churchill, G. A. (1979). A paradigm for developing better measures of marketing constructs. Journal of Marketing Research, 16(1), 64-73.

Cohen, J. (1988). Statistical power analysis for the behavioral sciences (2nd ed.). Hillsdale, NJ: Lawrence Erlbaum Associates.

Cronbach, L. J. (1951). Coefficient alpha and the internal structure of tests. Psychometrika, 16(3), 297-334.

Davison, A. C., \& Hinkley, D. V. (2003). Bootstrap methods and their application (2nd ed.). New York, NY: Cambridge University Press.

Diamantopoulos, A. (2006). The error term in formative measurement models: Interpretation and modeling implications. Journal of Modelling in Management, 1(1), 7-17.

Diamantopoulos, A., \& Winklhofer, H. (2001). Index construction with formative indicators: An alternative to scale development. Journal of Marketing Research, 38(2), 269-277.

Dibbern, J., Goles, T., Hirschheim, R. A., \& Jayatilaka, B. (2004). Information systems outsourcing: A survey and analysis of the literature. The Data Base for Advances in Information Systems, 35(4), 6-102.

Dijkstra, T. K. (1983). Some comments on maximum likelihood and partial least squares methods. Journal of Econometrics, 22(1/2), 67-90.

Dijkstra, T. K. (2009). Latent variables and indices: Herman Wold's basic design and partial least squares. In: V. Esposito Vinzi, W. W. Chin, J. Henseler \& H. Wang (Eds), Handbook of partial least squares: Concepts, methods, and applications. Berlin: Springer (in print). 
Edwards, J. R., \& Bagozzi, R. P. (2000). On the nature and direction of relationships between constructs and measures. Psychological Methods, 5(2), 155-174.

Efron, B., \& Tibshirani, R. J. (1993). An introduction to the bootstrap. New York, NY: Chapman Hall.

Eggert, A. (2007). Getting your PLS research published: A personal and interpersonal perspective. In: Proceedings of the academy of marketing science 2007 world marketing congress, July 11-14, Verona, Italy.

Esposito Vinzi, V., Ringle, C. M., Squillacciotti, S., \& Trinchera, L. (2007). Capturing and treating unobserved heterogeneity by response based segmentation in PLS path modeling: A comparison of alternative methods by computational experiments. ESSEC Research Center Working Paper 07019, ESSEC Business School Paris-Singapore, Paris.

Ewing, M. T., Salzberger, T., \& Sinkovics, R. R. (2005). An alternate approach to assessing cross-cultural measurement equivalence in advertising research. Journal of Advertising, 34(1), 17-36.

Falk, R. F., \& Miller, N. B. (1992). A primer for soft modeling. Akron, OH: University of Akron Press.

Festge, F., \& Schwaiger, M. (2007). The drivers of customer satisfaction with industrial goods: An international study. In: C. R. Taylor \& D.-H. Lee (Eds), Advances in international marketing (Vol. 18, pp. 179-207). Amsterdam: Elsevier.

Fornell, C. (1982). A second generation of multivariate analysis: An overview. In: C. Fornell (Ed.), A second generation of multivariate analysis (Vol. 1, pp. 1-21). New York, NY: Praeger.

Fornell, C. (1992). A national customer satisfaction barometer: The Swedish experience. Journal of Marketing, 56(1), 6-21.

Fornell, C., \& Bookstein, F. (1982). A comparative analysis of two structural equation models: LISREL and PLS applied to market data. In: C. Fornell (Ed.), A second generation of multivariate analysis (Vol. 1, pp. 289-323). New York, NY: Praeger.

Fornell, C., \& Larcker, D. F. (1981). Structural equation models with unobservable variables and measurement error: Algebra and statistics. Journal of Marketing Research, 18(3), 328-388.

Fornell, C., Lorange, P., \& Roos, J. (1990). The cooperative venture formation process: A latent variable structural modeling approach. Management Science, 36(10), 1246-1255.

Fornell, C., \& Robinson, W. T. (1983). Industrial organization and consumer satisfaction/ dissatisfaction. Journal of Consumer Research, 9(4), 403-412.

Gefen, D., Straub, D. W., \& Boudreau, M.-C. (2000). Structural equation modelling and regression: Guidelines for research practice. Communications of the Association for Information Systems, 4(7), 1-78.

Geisser, S. (1975). A predictive approach to the random effect model. Biometrika, 61(1), 101-107.

Gerpott, T., \& Jakopin, N. (2005). International marketing standardization and financial performance of mobile network operators - An empirical analysis. Schmalenbach Business Review, 57(3), 198-228.

Goodhue, D., Lewis, W., \& Thompson, R. (2006). PLS, small sample size, and statistical power in MIS research. In: HICSS '06: Proceedings of the 39th annual Hawaii international conference on system sciences, IEEE Computer Society, Washington, DC, pp. 202.2, CD-ROM, 10 pages.

Götz, O., Liehr-Gobbers, K., \& Krafft, M. (2009). Evaluation of structural equation models using the partial least squares (PLS) approach. In: V. Esposito Vinzi, W. W. Chin, 
J. Henseler \& H. Wang (Eds), Handbook of partial least squares: Concepts, methods, and applications. Berlin: Springer (in print).

Graham, J. L., Mintu, A. T., \& Rodgers, W. (1994). Explorations of negotiation behaviors in ten foreign cultures using a model developed in the United States. Management Science, 40(1), 72-95.

Green, D. H., \& Ryans, A. B. (1990). Entry strategies and market performance: Causal modeling of a business simulation. Journal of Product Innovation Management, 7(1), 45-58.

Grewal, R., Cote, J. A., \& Baumgartner, H. (2004). Multicollinearity and measurement error in structural equation models: Implications for theory testing. Marketing Science, 23(4), 519-529.

Gudergan, S. P., Ringle, C. M., Wende, S., \& Will, A. (2008). Confirmatory tetrad analysis for evaluating the mode of measurement models in PLS path modeling. Journal of Business Research, (in print).

Gustafsson, A., \& Johnson, M. D. (2004). Determining attribute importance in a service satisfaction model. Journal of Service Research, 7(2), 124-141.

Hahn, C., Johnson, M. D., Herrmann, A., \& Huber, F. (2002). Capturing customer heterogeneity using a finite mixture PLS approach. Schmalenbach Business Review, 54(3), 243-269.

Helm, S., Eggert, A., \& Garnefeld, I. (2009). Modelling the impact of corporate reputation on customer satisfaction and loyalty using PLS. In: V. Esposito Vinzi, W. W. Chin, J. Henseler \& H. Wang (Eds), Handbook of partial least squares: Concepts, methods, and applications. Berlin: Springer (in print).

Henseler, J. (2007). A new and simple approach to multi-group analysis in partial least squares path modeling. In: H. Martens, T. Næs \& M. Martens (Eds), PLS'07 international symposium on PLS and related methods - causalities explored by indirect observation (pp. 104-107). Norway: Matforsk, Ås.

Henseler, J., \& Fassott, G. (2009). Testing moderating effects in PLS path models: An illustration of available procedures. In: V. Esposito Vinzi, W. W. Chin, J. Henseler \& H. Wang (Eds), Handbook of partial least squares: Concepts, methods, and applications. Berlin: Springer (in print).

Higgins, C. A., Duxbury, L. E., \& Irving, R. H. (1992). Work-family conflict in the dual-career family. Organizational Behavior and Human Decision Processes, 51(1), 51-75.

Holzmüller, H. H., \& Kasper, H. (1991). On a theory of export performance: Personal and organizational determinants of export trade activities observed in small and mediumsized firms. Management International Review, 31(Special Issue), 45-70.

Holzmüller, H. H., \& Stöttinger, B. (1996). Structural modeling of success factors in exporting: Cross-validation and further development of an export performance model. Journal of International Marketing, 4(2), 29-55.

Howell, R. D., Breivik, E., \& Wilcox, J. B. (2007a). Is formative measurement really measurement? Reply to Bollen (2007) and Bagozzi (2007). Psychological Methods, 12(2), 238-245.

Howell, R. D., Breivik, E., \& Wilcox, J. B. (2007b). Reconsidering formative measurement. Psychological Methods, 12(2), 205-218.

Hsu, H.-H., Chen, W.-H., \& Hsieh, M.-J. (2006). Robustness testing of PLS, LISREL, EQS and ANN-based SEM for measuring customer satisfaction. Total Quality Management and Business Excellence, 17(3), 355-372.

Hulland, J. S. (1999). Use of partial least squares (PLS) in strategic management research: A review of four recent studies. Strategic Management Journal, 20(4), 195-204. 
Iacobucci, D., Grisaffe, D., Duhachek, A., \& Marcati, A. (2003). FAC-SEM: A methodology for modeling factorial structural equations models, applied to cross-cultural and crossindustry drivers of customer evaluations. Journal of Service Research, 6(1), 3-23.

Inkpen, A. C., \& Birkenshaw, J. (1994). International joint ventures and performance: An interorganizational perspective. International Business Review, 3(3), 201-217.

Jarvis, C. B., MacKenzie, S. B., \& Podsakoff, P. M. (2003). A critical review of construct indicators and measurement model misspecification in marketing and consumer research. Journal of Consumer Research, 30(2), 199-218.

Johansson, J. K., \& Yip, G. S. (1994). Exploiting globalization potential: U.S. and Japanese strategies. Strategic Management Journal, 15(8), 579-601.

Johnson, M. D., Herrmann, A., \& Gustafsson, A. (2002). Comparing customer satisfaction across industries and countries. Journal of Economic Psychology, 23(6), 749-769.

Jöreskog, K. G. (1982). The LISREL approach to causal model-building in the social sciences. In: K. G. Jöreskog \& H. O. Wold (Eds), Systems under indirect observation, Part I (pp. 81-100). Amsterdam: North-Holland.

Jöreskog, K. G., \& Goldberger, A. S. (1975). Estimation of a model with multiple indicators and multiple causes of a single latent variable. Journal of the American Statistical Association, 70(351), 631-639.

Jöreskog, K. G., \& Sörbom, D. (1996). LISREL 8: Structural equation modeling with the SIMPLIS command language. Chicago, IL: Scientific Software International.

Jöreskog, K. G., \& Wold, H. O. (Eds). (1982). The ML and PLS technique for modelling with latent variables: Historical and comparative aspects. In: Systems under indirect oberservation, Part I (pp. 263-270). Amsterdam: North-Holland.

Julien, P. A., \& Ramangalahy, C. (2003). Competitive strategy and performance of exporting SMEs: An empirical investigation of the impact of their export information search and competencies. Entrepreneurship Theory and Practice, 27(3), 227-245.

Keil, M., Tan, B. C., Wei, K.-K., Saarinen, T., Tuunainen, V., \& Wassenaar, A. (2000). A crosscultural study on escalation of commitment behavior in software projects. Management Information Systems Quarterly, 24(2), 299-325.

Krijnen, W. P., Dijkstra, T. K., \& Gill, R. D. (1998). Conditions for factor (in) determinacy in factor analysis. Psychometrika, 63(4), 359-367.

Lee, D. Y. (2000). Retail bargaining behaviour of American and Chinese customers. European Journal of Marketing, 34(1/2), 190-206.

Lee, D. Y. (2001). Power, conflict and satisfaction in IJV supplier - Chinese distributor channels. Journal of Business Research, 52(2), 149-160.

Lee, K.-H., Yang, G., \& Graham, J. L. (2006). Tension and trust in international business negotiation: American executives negotiating with Chinese executives. Journal of International Business Studies, 37(5), 623-641.

Lohmöller, J.-B. (1989). Latent variable path modeling with partial least squares. Heidelberg: Physica.

MacCallum, R. C., \& Browne, M. W. (1993). The use of causal indicators in covariance structure models: Some practical issues. Psychological Bulletin, 114(3), 533-541.

Mahmood, M. A., Bagchi, K., \& Ford, T. C. (2004). On-line shopping behavior: Cross-country empirical research. International Journal of Electronic Commerce, 9(1), 9-30.

Malhotra, N. K. (2001). Guest editorial: Cross-cultural marketing research in the twenty-first century. International Marketing Review, 18(3), 230-234. 
Mann, H. B., \& Whitney, D. R. (1947). On a test of whether one of two random variables is stochastically larger than the other. Annals of Mathematical Statistics, 18(1), 50-60.

Marcoulides, G. A. (2003). PLS model specification searches using optimization algorithms. In: M. Vilares, M. Tenenhaus, P. S. Coelho, V. Esposito Vinzi \& A. Morineau (Eds), PLS and related methods: Proceedings of the PLS'03 international symposium (pp. 75-86). Paris: Decisia.

Marcoulides, G. A., \& Saunders, C. (2006). PLS: A silver bullet? Management Information Systems Quarterly, 30(2), III-IX.

McDonald, R. P. (1996). Path analysis with composite variables. Multivariate Behavioral Research, 31(2), 239-270.

Mintu-Wimsatt, A., \& Graham, J. L. (2004). Testing a negotiation model on Canadian anglophone and Mexican exporters. Journal of the Academy of Marketing Science, 32(3), 345-356.

Money, R. B. (2004). Word-of-mouth promotion and switching behavior in Japanese and American business-to-business service clients. Journal of Business Research, 57(3), 297-305.

Money, R. B., \& Graham, J. L. (1999). Salesperson performance, pay, and job satisfaction: Tests of a model using data collected in the United States and Japan. Journal of International Business Studies, 30(1), 149-151.

Nakamura, M., Shaver, J. M., \& Yeung, B. (1996). An empirical investigation of joint venture dynamics: Evidence from US-Japan joint ventures. International Journal of Industrial Organization, 14(4), 521-541.

Nijssen, E. J., \& Douglas, S. P. (2008). Consumer world-mindedness, social-mindedness and store image. Journal of International Marketing, 16(3), 84-107.

Nunnally, J. C., \& Bernstein, I. H. (1994). Psychometric theory (3rd ed.). New York, NY: McGraw-Hill.

O'Cass, A., \& Fenech, T. (2003). Web retailing adoption: Exploring the nature of internet users web retailing behaviour. Journal of Retailing and Consumer Services, 10(2), 81-94.

Pavlou, P. A., \& Chai, L. (2002). What drives electronic commerce across cultures? A crosscultural empirical investigation of the theory of planned behaviour. Journal of Electronic Commerce Research, 3(4), 240-253.

Pinto, J. R., Rodríguez Escudero, A. I., \& Gutíerrez Cillán, J. (2008). Order, positioning, scope and outcomes of market entry. Industrial Marketing Management, 37(2), 154-166.

Pullman, M. E., Granzin, K. L., \& Olsen, J. E. (1997). The efficacy of cognition-and emotionbased "buy domestic" appeals: Conceptualization, empirical test, and managerial implications. International Business Review, 6(3), 209-231.

Reinartz, W., Krafft, M., \& Hoyer, W. D. (2004). The customer relationship management process: Its measurement and impact on performance. Journal of Marketing Research, 41(3), 293-305.

Rigdon, E. E. (1998). Structural equation modeling. In: G. A. Marcoulides (Ed.), Modern methods for business research (pp. 251-294). Mahwah, NJ: Lawrence Erlbaum Associates.

Rindskopf, D. (1984). Structural equation models. Sociological Methods and Research, 13(1), $109-119$.

Ringle, C. M. (2006). Segmentation for path models and unobserved heterogeneity: The finite mixture partial least squares approach. Research Papers on Marketing and Retailing 35, University of Hamburg, Hamburg. 
Ringle, C. M., Sarstedt, M., \& Mooi, E. A. (2009a). Response-based segmentation using finite mixture partial least squares: Theoretical foundations and an application to American customer satisfaction index data. Annals of Information Systems, in print.

Ringle, C. M., \& Schlittgen, R. (2007). A genetic algorithm segmentation approach for uncovering and separating groups of data in PLS path modeling. In: H. Martens, T. Næs \& M. Martens (Eds), PLS'07 International symposium on PLS and related methods - causalities explored by indirect observation (pp. 75-78). Norway: Matforsk, Ås.

Ringle, C. M., Wende, S., \& Will, A. (2005). SmartPLS 2.0 M3. Available at http:// www.smartpls.de

Ringle, C. M., Wende, S., \& Will, A. (2009b). The finite mixture partial least squares approach: Methodology and application. In: V. Esposito Vinzi, W. W. Chin, J. Henseler \& H. Wang (Eds), Handbook of partial least squares: Concepts, methods, and applications. Berlin: Springer (in print).

Ringle, C. M., Wilson, B., \& Götz, O. (2007). A Monte Carlo robustness study on formative measurement model specification in CBSEM and PLS. In: H. Martens, T. Næs \& M. Martens (Eds), PLS'07 international symposium on PLS and related methods Causalities explored by indirect observation (pp. 108-111). Norway: Matforsk, Ås.

Rossiter, J. R. (2002). The C-OAR-SE procedure for scale development in marketing. International Journal of Research in Marketing, 19(4), 305-335.

Sarkar, M. B., Echambadi, R., Cavusgil, S. T., \& Aulakh, P. S. (2001). The influence of complementarity, compatibility, and relationship capital on alliance performance. Journal of the Academy of Marketing Science, 29(4), 358-373.

Schneeweiß, H. (1991). Models with latent variables: LISREL versus PLS. Statistica Neerlandica, 45(2), 145-157.

Schneeweiß, H. (2001). Consistency at large in models with latent variables. In: K. Haagen, D. J. Bartholomew \& M. Deistler (Eds), Statistical modelling and latent variables (pp. 299-320). Amsterdam: North-Holland.

Shaffer, J. P. (1995). Multiple hypothesis testing. Annual Review of Psychology, 46, 561-584.

Singh, N., Fassott, G., Chao, M. C., \& Hoffmann, J. A. (2006a). Understanding international web site usage: A cross-national study of German, Brazilian, and Taiwanese online consumers. International Marketing Review, 23(1), 83-97.

Singh, N., Fassott, G., Zhao, H., \& Boughton, P. (2006b). A cross-cultural analysis of German, Chinese and Indian consumers perception of web site adaptation. Journal of Consumer Behaviour, 5(1), 56-68.

Steenkamp, J.-B., \& Baumgartner, H. (1998). Assessing measurement invariance in crossnational consumer research. Journal of Consumer Research, 25(1), 78-90.

Stone, M. (1974). Cross-validatory choice and assessment of statistical predictions. Journal of the Royal Statistical Society, 36, 111-147.

Stöttinger, B., \& Holzmüller, H. (2001). Cross national stability of an export performance model: A comparative study of Austria and the US. Management International Review, 41(1), 7-28.

Tenenhaus, M., Esposito Vinzi, V., Chatelin, Y.-M., \& Lauro, C. (2005). PLS path modeling. Computational Statistics \& Data Analysis, 48(1), 159-205.

Tsang, E. (2002). Acquiring knowledge by foreign partners from international joint ventures in a transition economy: Learning-by-doing and learning myopia. Strategic Management Journal, 23(9), 835-854. 
Venaik, S., Midgley, D. F., \& Devinney, T. M. (2005). Dual paths to performance: The impact of global pressures on MNC subsidiary conduct and performance. Journal of International Business Studies, 36(6), 655-675.

Vilares, M. J., Almeida, M. H., \& Coelho, P. S. (2009). Comparison of likelihood and PLS estimators for structural equation modeling: A simulation with customer satisfaction data. In: V. Esposito Vinzi, W. W. Chin, J. Henseler \& H. Wang (Eds), Handbook of partial least squares: Concepts, methods, and applications. Berlin: Springer (in print).

Werts, C. E., Linn, R. L., \& Jöreskog, K. G. (1974). Intraclass reliability estimates: Testing structural assumptions. Educational and Psychological Measurement, 34(1), 25-33.

Wilcoxon, F. (1947). Probability tables for individual comparisons by ranking methods. Biometrics, 3(3), 119-122.

Williams, L. J., Edwards, J. R., \& Vandenberg, R. J. (2003). Recent advances in causal modeling methods for organizational and management research. Journal of Management, 29(6), 903-936.

Wilson, B., Callaghan, W., Ringle, C. M., \& Henseler, J. (2007). Exploring causal path directionality for a marketing model using Cohen's path method. In: H. Martens, T. Næs \& M. Martens (Eds), PLS'07 international symposium on PLS and related methods - Causalities explored by indirect observation (pp. 57-61). Norway: Matforsk, Ås.

Wold, H. O. (1974). Causal flows with latent variables: Partings of the ways in the light of NIPALS modeling. European Economic Review, 5(1), 67-86.

Wold, H. O. (1982). Soft modeling: The basic design and some extensions. In: K. G. Jöreskog \& H. O. Wold (Eds), Systems under indirect observations, Part II (pp. 1-54). Amsterdam: North-Holland.

Wold, H. O. (1985). Partial least squares. In: S. Kotz \& N. L. Johnson (Eds), Encyclopedia of statistical sciences (Vol. 6, pp. 581-591). New York, NY: Wiley.

Wold, H. O. (1989). Introduction to the second generation of multivariate analysis. In: H. O. Wold (Ed.), Theoretical empiricism: A general rationale for scientific model-building (pp. VIII-XL). New York, NY: Paragon House. 